\title{
The Role of Surface Functional Groups in the Adsorption Kinetics of Water Vapor on Activated Carbon
}

\author{
Ashleigh J. Fletcher, Yaprak Uygur' and K. Mark Thomas* \\ Northern Carbon Research Laboratories, School of Natural Sciences, Bedson Building, \\ Newcastle University, Newcastle upon Tyne, NE1 7RU, U.K. \\ (* Author to whom all correspondence should be addressed: E-mail: mark.thomas@ncl.ac.uk)
}

\begin{abstract}
Activated carbons have both hydrophilic surface oxygen functional groups, which act as primary adsorption centers for water vapor and hydrophobic graphene layers on which non-polar species are primarily adsorbed. The aim of this research was to investigate the effects of oxygen surface functional groups, in activated carbons, on the adsorption characteristics of water vapor. Activated carbon G, was oxidized using nitric acid and then heat treated in the range $387-894 \mathrm{~K}$ to produce a suite of adsorbents with varying oxygen contents in the range $0.4-21.5 \%$, but very similar porous structure characteristics, thereby minimizing effects due to changes in porous structure. The type and concentration of surface oxygen groups present on each sample was assessed using TPD, FTIR and Boehm titration methods. Water vapor adsorption at low relative pressure was dramatically enhanced by the presence of functional groups, in particular, carboxylic groups. Kinetic profiles for each pressure increment were modeled using a set of nested kinetic models, which allow the adsorption kinetics to be interpreted in relation to the adsorption mechanism. The results establish a clear relationship between water adsorption kinetics and the type and concentration of oxygen surface functional groups. A linear relationship was observed between the rate constants in the low pressure region and the inverse of the Henry's Law constant. This indicates the importance of adsorbate-adsorbent interactions in water adsorption kinetics and is consistent with a site-to-site hopping mechanism between functional groups.
\end{abstract}

\footnotetext{
${ }^{\dagger}$ Current address: Karadeniz Teknik Üniversitesi , 61080 Trabzon, Turkey.
} 


\section{Introduction}

Activated carbons are used extensively for the adsorption of trace amounts of environmentally unfriendly organic vapor pollutants in competitive adsorption situations. Adsorption of organic pollutants from the atmosphere involves competitive adsorption with nitrogen, oxygen and water vapor. Water vapor can displace organic species from activated carbon and slow adsorption kinetics, Also, pre-adsorbed water content will vary with ambient weather conditions. ${ }^{1}$ Hence the adsorption characteristics of water vapor are important when considering the removal of organic vapor pollutants from air and process streams by adsorption on activated carbons.

The mechanism for water vapour adsorption on carbon surfaces is more complex than that of non-associating molecules such as hydrocarbons or nitrogen. ${ }^{2}$ Organic species are primarily adsorbed on hydrophobic sites, mainly comprising graphene layers; while water vapor adsorption occurs via initial, strong adsorption on hydrophilic surface functional groups. Generally, increasing oxygen functional group concentration increases adsorption of water vapor at low-pressure $\left(\mathrm{p} / \mathrm{p}^{0}<0.5\right){ }^{3-6} \mathrm{~A}$ linear relationship was observed between low-pressure adsorption of water vapor and the number of hydrophilic sites. ${ }^{7-9}$

Muller et al. used Grand Canonical Monte Carlo simulations to investigate the effect of changing functional group concentration on isotherm shape for non-porous and porous activated carbons. The water molecules adsorbed on the hydrophilic surface groups act as nucleation sites for further adsorption of water, and threedimensional clusters and networks develop with increasing relative pressure. Molecular modeling simulations of the density and geometric arrangement of active surface sites, showed a pronounced effect on adsorption. Capillary condensation 
occurred for low active adsorption site density; whereas higher densities showed continuous filling of the porosity. ${ }^{2}$

Water vapor adsorption kinetics for activated carbons are complex because of the presence of both a range of functional groups and a distribution of pore sizes, and both are important in assessing the performance of activated carbon. The adsorption/desorption kinetics of water vapor on carbons with widely different pore structures showed that in all cases the fastest rates were observed for adsorption on primary adsorption centers at low relative pressures. ${ }^{10,11}$ Water vapor adsorption/desorption kinetics on porous carbons and carbon molecular sieves varied considerably with vapor pressure, and were related to the mechanism of adsorption/desorption. ${ }^{12}$ However, there is no information available in the literature on the effect of functional groups on adsorption kinetics for porous materials.

The effect of pore size on adsorption kinetics for porous materials is well established. Activated diffusion occurs when the pore size and molecular dimensions are similar. Kinetic molecular sieving is used in pressure swing adsorption for separation of $\mathrm{N}_{2}$ and $\mathrm{O}_{2}$ from air. Adsorption of water vapor on activated carbon involves initial adsorption on functional groups but the role and relative importance of various types of functional groups in adsorption dynamics has not been established. The objectives of this study were to synthesize a series of activated carbons with very similar narrow pore size distributions, but with a wide range of functional group concentration, thereby allowing effects due to functional groups to be investigated independent of changes in pore structure. Detailed investigation of the influence of oxygen functional groups on water vapor adsorption kinetics showed, for the first time, the influence of surface chemistry on adsorption kinetics in porous materials. 


\section{Experimental}

\subsection{Materials Used}

Carbon $\mathrm{G}$, a steam activated coconut shell based activated carbon with particle size fraction range $1-2 \mathrm{~mm}$, was obtained from Pica, Vierzon, France. The adsorbates used were nitrogen (99.9995\% purity) and carbon dioxide (99.999\%), supplied by BOC, and high purity water. Nitric acid (70 wt \%), used for sample oxidation, was supplied by Aldrich, UK.

\subsection{Nitric Acid Oxidation of Carbon G}

Carbon $\mathrm{G}$ was refluxed in $7.5 \mathrm{M} \mathrm{HNO}_{3}$ solution for $48 \mathrm{~h}$, before Soxhlet extraction with water to constant $\mathrm{pH}$, to remove residual $\mathrm{HNO}_{3}$ and any water soluble materials. The resulting material was vacuum dried at $348 \mathrm{~K}$ and designated GN.

\subsection{Heat Treated Activated Carbons}

2.3.1 Heat Treatment Procedure GN was heat-treated to a range of sample temperatures ( 387 to $894 \mathrm{~K}$ ) under ultra-high vacuum and held at the maximum heat treatment temperature for $3 \mathrm{~h}$. Heat treatment progressively modified the surface functional groups present. The resultant GN series of carbons were designated as the code of the original carbon and the heat treatment temperature (HTT) in K, e.g. GN400 is G oxidized using nitric acid and heat-treated to $400 \mathrm{~K}$ for 3 hours. Weight loss profiles for each heat treatment were recorded, and after each heat treatment the water vapor adsorption isotherm was recorded.

2.3.2 Laboratory Heat Treatment GN was heat-treated at various temperatures in the range 387 to $894 \mathrm{~K} .10 \mathrm{~g}$ of sample was placed in a quartz tube in a flow of argon $\left(50 \mathrm{~mL} \mathrm{~min}{ }^{-1}\right)$. Samples were kept at the HTT for $12 \mathrm{~h}$.

\subsection{Carbon Characterization}

2.4.1 Elemental Analysis Carbon, hydrogen, nitrogen and oxygen analyses were performed by Elemental Micro-Analysis Ltd, Okehampton, Devon, UK. 
2.4.2 Proximate Analysis A Stanton Redcroft STA 780 thermobalance was used to determine the proximate analyses of the carbon samples. Approximately $50 \mathrm{mg}$ of carbon sample was heated in a constant flow of $50 \mathrm{~mL} \mathrm{~min}^{-1}$ of $\mathrm{N}_{2}$ with a heating rate of $50 \mathrm{~K} \mathrm{~min}^{-1}$ to a series of temperatures where the weight losses were equilibrated. The weight loss values after heating to $400 \mathrm{~K}$ and $1200 \mathrm{~K}$ were recorded and these correspond to the moisture and volatile matter contents, respectively. The fixed carbon residue at $1200 \mathrm{~K}$ was combusted in air at $1100 \mathrm{~K}$. The weight of the residue corresponded to the ash content.

\subsection{Determination of Surface Oxygen Functional Groups}

2.5.1 Temperature Programmed Desorption (TPD) Studies were carried out using a Thermal Science STA 1500 thermogravimetric analyzer (TGA) connected to a VG Quadrupole 300 amu mass spectrometer by a heated stainless steel capillary, lined with deactivated fused silica. $\sim 5 \mathrm{mg}$ of carbon was placed in a sample bucket and heated from ambient temperature to $1373 \mathrm{~K}$ (heating rate $15 \mathrm{~K} \mathrm{~min}^{-1}$ ) under flowing $\operatorname{argon}\left(50 \mathrm{~mL} \mathrm{~min}{ }^{-1}\right)$. Evolved gases were sampled and analyzed by mass spectrometry throughout the desorption process. Mass to charge $(\mathrm{m} / \mathrm{z})$ values of 18 , 28 and 44 were monitored, corresponding to evolution of $\mathrm{H}_{2} \mathrm{O}, \mathrm{CO}$ and $\mathrm{CO}_{2}$, respectively.

2.5.2 Titration Studies Carbon surface functional groups were evaluated by the method of Boehm. ${ }^{13} \sim 0.2 \mathrm{~g}$ of carbon was placed in $25 \mathrm{~mL}$ of the following $0.1 \mathrm{~N}$ solutions: sodium hydroxide, sodium carbonate, sodium bicarbonate and hydrochloric acid. The mixtures were allowed to stand under nitrogen for $48 \mathrm{hr}$ at room temperature, before separation by filtering. The excess base and acid were titrated with $0.1 \mathrm{~N} \mathrm{HCl}$ and $0.1 \mathrm{~N} \mathrm{NaOH}$, respectively. The concentration of acidic sites were calculated using the assumption that $\mathrm{NaOH}$ neutralizes carboxylic, phenolic and 
lactonic groups; $\mathrm{Na}_{2} \mathrm{CO}_{3}$ neutralizes carboxylic and lactonic and $\mathrm{NaHCO}_{3}$ neutralizes only carboxylic groups. The concentration of surface basic sites was calculated from the titer for hydrochloric acid.

2.5.3 Fourier Transform Infrared Spectroscopy (FTIR) Infrared spectra were recorded on a Nicolet 20-PCIR Fourier Transform Infrared Spectrometer with a CsI optics DTGS detector, with a resolution of $4 \mathrm{~cm}^{-1}$. Discs were prepared by compressing mixtures of $0.5 \%$ finely ground carbon sample in $\mathrm{KBr}$.

\subsection{Adsorption Studies}

The apparatus used was an intelligent gravimetric analyzer (IGA) supplied by Hiden Analytical Ltd., Warrington, UK, which is an ultrahigh vacuum system that allows isotherms and the corresponding kinetics of adsorption to be determined, for set pressure steps. ${ }^{14}$ The balance and pressure control systems were fully thermostated to $0.2 \mathrm{~K}$ to eliminate changes in the external environment. The microbalance had a 1 $\mu \mathrm{g}$ long-term stability with a weighing resolution of $0.2 \mu \mathrm{g}$. The carbon sample (100 \pm $1 \mathrm{mg}$ ) was outgassed to a constant weight, at $<10^{-6} \mathrm{~Pa}$, at an appropriate HTT. The water used to generate the vapor was degassed fully by repeated evacuation and vapor equilibration cycles of the liquid supply side of the vapor reservoir. The gas/vapor pressure was gradually increased, over $\sim 30 \mathrm{~s}$ to prevent microbalance disruption, until the desired value was achieved. Pressure control was via two transducers with ranges $0-0.2$ and $0-10 \mathrm{kPa}$ (accurate to $0.02 \%$ of the specified range). The pressure was maintained at the set point by active computer control of the inlet/outlet valves throughout the experiment. Mass uptake was measured as a function of time and the approach to equilibrium monitored in real time with a computer algorithm. After equilibrium was established, the gas/vapor pressure was increased to the next set

pressure value and the subsequent uptake measured until equilibrium was 
reestablished. Increase in weight due to adsorption for each pressure step was used to calculate kinetic parameters for adsorption using an appropriate kinetic model.

Errors in the calculated rate constants were typically $< \pm 2 \%$. Sample temperature was monitored throughout the experiment and variation was minimal $(< \pm$ $0.05 \mathrm{~K})$. Adsorption isotherms for various temperatures were carried out in steps of relative pressure, thereby corresponding to steps of surface coverage. Saturated vapor pressures were calculated using: ${ }^{15}$

$$
\log p^{0}=A-\frac{B}{T+C}
$$

where $p^{0}$ is the saturated vapor pressure (Torr), T is the temperature $\left({ }^{\circ} \mathrm{C}\right)$ and $\mathrm{A}, \mathrm{B}$ and $\mathrm{C}$ are constants defined by the adsorbate. The parameters used were: carbon dioxide (77 -303 K): A) 7.81024 B) 995.705 C) 293.475 ; nitrogen (75 - $373 \mathrm{~K})$ : A) 6.49457 B) $255.68 \mathrm{C}) 266.550$ and water $(263-383 \mathrm{~K})$ : A) $8.09553 \mathrm{~B}) 1747.32 \mathrm{C}) 235.074$.

\section{Results and Discussion}

\subsection{Carbon Characterization}

3.1.1 Proximate and Ultimate Analysis Analytical results for original, oxidized and heat-treated carbons (Tables 1 and 2) show that oxidation with $\mathrm{HNO}_{3}$ incorporates a large amount of oxygen functionality, as shown by the high oxygen and volatile matter contents compared with the original carbon G. Heat treatment results in progressive mass loss, with a gradual decrease in volatile matter and oxygen content with increasing HTT, due to desorption of oxygen functionalities. Figures $1 \mathrm{a}$ and $1 \mathrm{~b}$ show that oxygen content decreases linearly with increasing HTT while mass loss increases linearly with increasing HTT. Heat treatment of G to $913 \mathrm{~K}$ decreases the oxygen content from $\sim 2.8 \mathrm{wt} \%$ to $0.4 \mathrm{wt} \%$ due to loss of surface oxygen groups 
incorporated in the steam activation procedure. The hydrogen content decreased from 1.3 to $0.76 \mathrm{wt} \%$ while the nitrogen content remained constant with increasing HTT for the $G$ heat treated carbon series. The nitrogen content for the GN series was significantly higher that the original $G$ carbon indicating that a small amount of nitrogen was incorporated by nitric acid treatment. Since the nitrogen content is small $(\sim 1 \%)$ and does not vary, the influence of nitrogen functional groups on adsorption characteristics is small and invariant for the GN series of carbons. Ash content ( 1-1.5 $\%$ ) was approximately the same for all oxidized carbons studied and lower than the original $\mathrm{G}$ carbon $(\sim 3 \%)$. This is attributed to part of the ash content being dissolved by the nitric acid.

3.1.2 Pore Structure Characteristics Nitrogen ( $77 \mathrm{~K})$ and carbon dioxide ( $273 \mathrm{~K}$ ) adsorption isotherms were classified as Type I, in the IUPAC classification for all carbons studied. ${ }^{16}$ The total pore and micropore $(<2 \mathrm{~nm})$ volumes were determined from nitrogen adsorption at $77 \mathrm{~K}$ and the micropore volume $(<0.7 \mathrm{~nm})$ was determined from carbon dioxide adsorption at $273 \mathrm{~K} .{ }^{17-19}$ The variations of the total and micropore volumes with heat treatment temperature are shown in Figure 2. It is apparent that the porous structure was only altered slightly in the HTT range studied. This series was almost completely microporous (average $0.428 \pm 0.012 \mathrm{~cm}^{3} \mathrm{~g}^{-1}<2$ $\mathrm{nm}$ ) with a major part being ultra-microporous (average $0.252 \pm 0.011 \mathrm{~cm}^{3} \mathrm{~g}^{-1}<0.7$ $\mathrm{nm}$ ). In contrast, total pore volumes increased slightly for HTT (average total pore volume $\left.=0.452 \pm 0.023 \mathrm{~cm}^{3} \mathrm{~g}^{-1}\right)$. The pore size distribution obtained for $\mathrm{G}$ using $\mathrm{BJH}$ analysis $^{20}$ for nitrogen adsorption at $77 \mathrm{~K}$ shows that the maximum pore size was $\sim 2$ $\mathrm{nm}$ (see Supporting Information). This is on the edge of the validity of the BJH method but shows the absence of significant amounts of mesoporosity. The DubininStoeckli correlation method was used to calculate $X$, the mean radius of microporosity 
and the characteristic energy in the DR equation $\left(\mathrm{CO}_{2}\right.$ at $\left.273 \mathrm{~K}, \beta=0.35\right){ }^{21}$ The average pore radii and characteristic energy for $G$ and the GN series were $4.282 \pm$ $0.056 \AA$ and $26.83 \pm 0.24 \mathrm{~kJ} \mathrm{~mol}^{-1}$, respectively.

Adsorption of $\mathrm{CO}_{2}$ on $\mathrm{G} 913$ at $273 \mathrm{~K}$ gave slow kinetics due to thermal annealing of the structure, which results in narrowing of the porosity. The average pore radii and characteristic energy for G913 calculated by the Dubinin-Stoeckli method were $3.81 \pm 0.09 \AA$ and $28.93 \pm 0.11 \mathrm{~kJ} \mathrm{~mol}^{-1}$, respectively. Therefore, $298 \mathrm{~K}$ was used for $\mathrm{CO}_{2}$ adsorption on $\mathrm{G} 913$ and a markedly lower micropore volume $(0.166$ $\left.\mathrm{cm}^{3} \mathrm{~g}^{-1}\right)$ was obtained for G913 than the heat-treated series $\left(0.227-0.261 \mathrm{~cm}^{3} \mathrm{~g}^{-1}\right)$ and the raw carbon, $\mathrm{G}\left(0.316 \mathrm{~cm}^{3} \mathrm{~g}^{-1}\right)$. In contrast, the total pore volume $\left(0.436 \mathrm{~cm}^{3} \mathrm{~g}^{-1}\right)$ was in the range for the heat-treated series and $\mathrm{G}\left(0.410-0.478 \mathrm{~cm}^{3} \mathrm{~g}^{-1}\right)$.

3.1.3 Titration Studies Activated carbon surfaces have amphoteric character. ${ }^{22,23}$ The Boehm method was used to evaluate the type and quantity of carbon surface groups with specific acid groups neutralized using selected bases ${ }^{24}$ and surface basic groups were determined by titration with hydrochloric acid. ${ }^{25}$ Figure 3 shows the variation of acidic functional groups determined by this method with HTT. The total quantity of acidic functional groups decreases linearly with HTT. The oxygen content also decreases linearly with increasing temperature (see Figure 1). Carboxylic acid groups are the least thermally stable oxygen surface groups and virtually all of the carboxylic acid groups are decomposed by $894 \mathrm{~K}$ whereas the amounts of lactone remained relatively unchanged and phenolic groups decreased by only $\sim 50 \%$, indicating greater stability towards heat treatment. Oxidation of $\mathrm{G}$ by $\mathrm{HNO}_{3}$ produced considerable amounts of acidic groups on the carbon surface; approximately half of the total acidity in GN was due to carboxylic groups. 
3.1.4 Temperature Programmed Desorption The thermal decomposition of oxygen functional groups in carbons to form $\mathrm{CO}$ and $\mathrm{CO}_{2}$ has been widely investigated. ${ }^{26-28}$ The interpretation of TPD data is complex because of the distribution of different environments for functional groups and surface group mobility is significant at high temperature. ${ }^{29}$ The total $\mathrm{CO}_{2} / \mathrm{CO}$ ratios can be used quantitatively, while the identification of specific functional groups is semi-quantitative. ${ }^{27}$ Carboxylic and lactones decompose to give $\mathrm{CO}_{2}$ in the temperature range $473-923 \mathrm{~K}$, while less acidic (phenol and carbonyl) and basic (pyrone) groups are desorbed mainly as $\mathrm{CO}$ or $\mathrm{CO}+\mathrm{CO}_{2}$ in the temperature range $773-1273 \mathrm{~K} \cdot{ }^{27} \mathrm{CO}$ desorption occurred at higher temperatures than the corresponding $\mathrm{CO}_{2}$ and reached a maximum at $\sim 973 \mathrm{~K}$. A small amount of NO was desorbed for the two lowest temperature treated carbons, due to the decomposition of small amounts of pyridine-N-oxide groups incorporated by the nitric acid oxidation procedure. ${ }^{30}$

The total $\mathrm{CO}_{2} / \mathrm{CO}$ ratio decreases with increasing HTT and these results are similar to those obtained previously ${ }^{31}$ (see Supporting Information). The low temperature peak $(\sim 543 \mathrm{~K})$, which is an indication of the presence of carboxylic acid groups, was not observed in the $\mathrm{CO}_{2}$ profiles of the samples with HTT $>562 \mathrm{~K}$. This is within the temperature range for decomposition of carboxylic acid and lactone groups during TPD given in the literature $(473-923 \mathrm{~K}) .{ }^{27}$ The low, intermediate and high temperature peaks were associated with desorption of carboxylic, anhydride, lactone etc. groups. $\mathrm{CO}$ is also evolved in the temperature range of the two highest temperature peaks. The TPD profiles obtained are consistent with analytical data and Boehm titration results.

3.1.5 Fourier Transform Infrared (FTIR) Spectroscopy. Heat treatment of GN to produce the series of carbons decreased the intensities of bands at $1182 \mathrm{~cm}^{-1}$ 
(contributions from $\mathrm{C}-\mathrm{O}$ stretching and $\mathrm{O}-\mathrm{H}$ bending modes in phenolic, carboxylic acid groups ${ }^{32}$ ), $1576 \mathrm{~cm}^{-1}$ (aromatic ring stretching mode and conjugated carbonyl groups) and $1717 \mathrm{~cm}^{-1}$ (stretching vibrations of carbonyl groups $(\mathrm{C}=\mathrm{O})$ in carboxylic acid groups) until they were very weak for HTT $~ 900 \mathrm{~K}$ ( see Supporting Information). Heat treatment also broadens the bands at $1717 \mathrm{~cm}^{-1}$ and $1734 \mathrm{~cm}^{-1}$ (anhydrides) to produce a flat top peak with a gradual decrease in intensity with increasing HTT. Only the band at $1635 \mathrm{~cm}^{-1}$ (associated with highly conjugated carbonyl groups ${ }^{33}$ ) is present for HTT $=894 \mathrm{~K}$. These trends are consistent with the progressive decomposition of carboxylic, lactone, phenolic etc. groups with increasing HTT.

\subsection{Water Vapor Adsorption Isotherms on Activated Carbon}

Water vapor adsorption isotherms for the GN series of carbons are shown in Figure 4 and are all Type $\mathrm{V}$ in the IUPAC Classification Scheme. The porous structure characteristics do not change markedly with heat treatment and therefore, the major changes in water vapor isotherm shape are due to changes in functional group concentrations. Differences at high $\mathrm{p} / \mathrm{p}^{0}$ are much smaller than at low relative pressure since the former is determined by filling of the total pore volume, which does not change markedly. However, while the activated carbons with the highest oxygen concentrations have the overall Type $\mathrm{V}$ isotherm shape with a point of inflexion, they have much larger uptakes at low relative pressure. The decrease in functional group concentration with HTT shifts the main uptake region of the isotherm, corresponding to cluster development and merging, leading to pore filling at higher $\mathrm{p} / \mathrm{p}^{0}$. Water adsorption isotherms for the heat-treated carbons show linearity at low pressure indicating that Henry's law is obeyed. The variation of the Henry's law constant with oxygen content for the series of carbons is shown in Figure 5. It is evident that there is a linear correlation for the five carbons with the highest HTTs in the series while the 
carbons with the two lowest HTTs (highest oxygen contents) deviate markedly from the line. This difference is ascribed to large amounts of carboxylic acid groups for the two samples with the lowest HTTs.

Figure 2 shows that both the total pore volumes obtained from nitrogen $\left(\mathrm{V}_{\mathrm{N}_{2}}\right)$ and water vapor $\left(\mathrm{V}_{\mathrm{H}_{2} \mathrm{O}}\right)$ adsorption increase slightly with increasing heat treatment temperature for the series of carbons. The ratio $\mathrm{V}_{\mathrm{H}_{2} \mathrm{O}} / \mathrm{V}_{\mathrm{N}_{2}}$ decreases with increasing HTT and decreasing oxygen content. which corresponds to increasing hydrophobicity of the surface. The ratio $\mathrm{V}_{\mathrm{H}_{2} \mathrm{O}} / \mathrm{V}_{\mathrm{N}_{2}}$ was $\sim 1$ for carbons $\mathrm{HTT}<473 \mathrm{~K}$ and decreased to an average value $\sim 0.87$ for carbons with $\mathrm{HTT}>560 \mathrm{~K} . \mathrm{V}_{\mathrm{H}_{2} \mathrm{O}} / \mathrm{V}_{\mathrm{N}_{2}}$ ratios in the range 0.22-1 have been reported peviously. ${ }^{12,34-3637}$ The results indicate that surface chemistry influences the density of adsorbed water confined in pores.

3.2.1 Dubinin-Serpinsky (DS) Analysis Dubinin and Serpinsky proposed that water vapor adsorption isotherms can be described by the following equation: ${ }^{38}$

$$
a=\frac{a_{o} c\left(p / p^{0}\right)}{\left(1-c\left(p / p^{0}\right)\right)}
$$

where $a_{o}$ is the number of primary adsorption centers and $a$ is the amount adsorbed for relative pressure, $p / p^{0}$. Parameters obtained from Dubinin-Serpinsky analysis of the water adsorption data is shown in Table 3. Linear portions of the D-S graphs shift to lower $\mathrm{p} / \mathrm{p}^{0}$ with increasing oxygen content. The amount of primary sites $\left(a_{o}\right)$ decreases with increasing HTT, due to decomposition of oxygen surface functional groups. The variation of $a_{0}$ with oxygen content shows that the two carbons with the lowest HTTs are distinctly different from the other carbons in the series.

\subsubsection{Relationships between Isotherm Parameters and Functional groups}

The porous structure characteristics in the GN carbon series do not change significantly for the series (see Figure 2). The linear correlations between the oxygen 
content (Figure 1a), mass loss during heat treatment (Figure 1b) and total acidity of surface groups (Figure 3) with heat treatment shows the progressive change in functional group concentration and hence surface chemistry, which influences water vapor adsorption isotherm characteristics. This is most marked at low $\mathrm{p} / \mathrm{p}^{0}$ (low surface coverage) when water is initially adsorbed on surface functional groups, rather than high $\mathrm{p} / \mathrm{p}^{0}$ where associative effects involving hydrogen bonding between water molecules occurs. The variation of the Henry's law constant $\left(\mathrm{K}_{\mathrm{H}}\right)$ and DS primary adsorption centers $\left(a_{0}\right)$ with oxygen content shows that the two lowest temperature treated carbons (GN387 and GN471) differ substantially from the other carbons in the series (see Figure 5). The variation of $\mathrm{K}_{\mathrm{H}}$ with total acid functional group concentration is shown in Figure 6a. It is apparent that the adsorption characteristics of the two low temperature heat treated carbons differ from the other carbons in the series, but this is less marked than the correlations in Figure 5. The variation of $\mathrm{K}_{\mathrm{H}}$ with carboxylic acid concentration, determined by the titration results, shows a similar trend (see Supporting Information). Figure $6 \mathrm{~b}$ shows that $\mathrm{K}_{\mathrm{H}}$ varies approximately linearly with the TPD total $\mathrm{CO}_{2} / \mathrm{CO}$ ratio for all the carbons in the series, which shows that the functional groups, which decompose to give $\mathrm{CO}_{2}$, have a marked effect on water vapor adsorption at low relative pressure. Therefore, the GN carbon series were divided into 2 sub-series, GNL comprising of carbons GN387 and GN471 $(\mathrm{HTT}<473 \mathrm{~K})$ and $\mathrm{GN}_{\mathrm{H}}$ comprising of GN562 - GN894 (HTT > $\left.560 \mathrm{~K}\right)$.

\subsection{Adsorption Kinetics}

Normalized kinetic profiles for small pressure increments for adsorption on porous materials can be described using a series of nested models based on a double stretched exponential (DSE) model. This model describes a two process mechanism system, which is expressed as follows: 


$$
\frac{M_{t}}{M_{e}}=A_{1}\left(1-e^{-\left(k_{1} t\right)^{\beta_{1}}}\right)+\left(1-A_{1}\right)\left(1-e^{-\left(k_{2} t\right)^{\beta_{2}}}\right)
$$

where $M_{t}$ is the uptake at time $t, M_{e}$ is the equilibrium uptake, $k_{1}$ and $k_{2}$ are the rate constants, $\beta_{1}$ and $\beta_{2}$ are the exponents and $A_{1}$ and $\left(1-A_{1}\right)$ are the fractional contributions for process mechanism corresponding to adsorption rate constants $k_{l}$ and $k_{2}$, respectively. This model describes two kinetic processes each with a distribution of relaxation times. The double exponential (DE) model is a nested model of the DSE model with $\beta_{1}=\beta_{2}=1$ and is described as follows:

$$
\frac{M_{t}}{M_{e}}=A_{1}\left(1-e^{-k_{1} t}\right)+\left(1-A_{1}\right)\left(1-e^{-k_{2} t}\right)
$$

Diffusion of ethanol and methanol into $\mathrm{Ni}_{2}\left(4,4^{\prime} \text { bipyridine }\right)_{3}$. $\left(\mathrm{NO}_{3}\right)_{4}$ porous framework materials templated with ethanol (E) and methanol (M) followed the DE model. Since there are equal numbers of pore cavities and windows in these materials as shown from crystallographic studies, diffusion through both structural features have equal contributions $\left(\mathrm{A}_{1}=0.5\right)$. The kinetics can be described by two processes with single relaxation times, a) slow diffusion through windows with high activation energy and b) fast diffusion along pore cavities with low activation energy..$^{39,40}$

The stretched exponential (SE) model is also a nested model of the DSE model where $k_{1}=k_{2}=k$ and $\beta_{1}=\beta_{2}=\beta$ and is described by the following equation

$$
\frac{M_{t}}{M_{e}}=1-e^{-(k t)^{\beta}}
$$

The derivation of the stretched exponential model for different physical mechanisms has an underlying common mathematical structure. The SE model is 1dimensional with a distribution of relaxation times when $\beta=0.5$, and 3-dimensional with a single relaxation time when $\beta=1 .^{41}$ The SE model was observed in quantum 
molecular sieving adsorption and desorption of $\mathrm{H}_{2}$ and $\mathrm{D}_{2}$ on CMS T3A at $77 \mathrm{~K}$ and a porous carbon. ${ }^{42}$

The Linear Driving Force (LDF) model is a special nested case of the SE model when $\beta=1$ and is described by the equation:

$$
\frac{M_{t}}{M_{e}}=1-e^{-k t}
$$

A plot of $\ln \left(1-M_{t} / M_{e}\right)$ versus time is linear with a gradient equal to the rate constant $(k)$. The LDF model is observed for adsorption of gases such as oxygen, nitrogen, carbon dioxide, argon and krypton, on a carbon molecular sieve (CMS) and vapors on activated carbons. ${ }^{1,11,43-48}$ The change from LDF to SE represents a change from a single relaxation time to a distribution of relaxation times.

The criteria for an acceptable fit of the experimental data to the kinetic model were that $99 \%$ of residuals should be within \pm 0.02 for the model with the least numbers of variables. Comparison of Linear Driving Force (LDF), Stretched Exponential (SE), Double Exponential (DE) and Double Stretched Exponential (DSE) models is difficult because of the different number of variables in each kinetic model. Similarities between the shapes of DE and SE curves produce additional difficulties in distinguishing between models. The most appropriate model was selected on the basis of the lowest number of variables, which fitted the experimental data and was consistent with the surface chemistry.

\subsubsection{Kinetic Models for Water Vapor Adsorption on GN Series Activated}

\section{Carbons}

The water vapor adsorption kinetic profiles for the $\mathrm{GN}_{\mathrm{L}}$ sub-series $(\mathrm{GN} 387$ and GN471) fitted the DE model. A typical kinetic profile for GN471 for pressure increment $\mathrm{p} / \mathrm{p}^{0}, 0.125-0.150$, and the corresponding fit for the DE model are shown in 
Figure 7a. The residuals were within \pm 0.02 and, therefore, it was not necessary to go to the increased complexity of the DSE model with two additional exponent parameters. The observation that the adsorption kinetics follow the DE model is consistent with the presence of two distinct processes, which are attributed to different $\mathrm{H}_{2} \mathrm{O}$-functional group interactions.

The adsorption kinetics for the $\mathrm{GN}_{\mathrm{H}}$ sub-series follow the SE model. A typical kinetic profile, also for pressure increment $\mathrm{p} / \mathrm{p}^{0}, 0.125-0.150$, for water vapor adsorption on GN629 and the corresponding fit for the SE model are shown in Figure 7b. The residuals were within \pm 0.01 showing that the SE model provides an excellent fit for the experimental data. This is consistent with a distribution of relaxation times due to the presence of various functional groups with a distribution of properties due to a range of structural environments in the carbon structure.

\subsubsection{The Variation of Water Vapor Adsorption Kinetic Parameters with p/p ${ }^{0}$.}

The dimensions of the water molecule are $3.226 \times 2.917 \times 3.888 \AA .{ }^{49}$ Adsorption of $\mathrm{H}_{2} \mathrm{O}$ on a CMS used for air separation, where diffusion through the barriers formed by the carbon deposit was the determining step for nitrogen/oxygen adsorption, had water adsorption kinetic parameters similar to those in nonkinetically selective porous materials. ${ }^{10}$ This indicates that the water vapour adsorption kinetics were not limited by diffusion through the barriers in the very narrow selective porosity resulting from the carbon deposit in the CMS.

The variation of the $\mathrm{DE}$ kinetic parameters with $\mathrm{p} / \mathrm{p}^{0}$ for the $\mathrm{GN}_{\mathrm{L}}$ sub-series is shown in Figure 8. It is apparent that the fast component, which has similar values to the SE kinetic parameters to the $\mathrm{GN}_{\mathrm{H}}$ sub-series, decreases with increasing relative pressure up to $\mathrm{p} / \mathrm{p}^{0} \sim 0.2$. However, the fractional contribution of this component increases from $\sim 0.3$ at $\mathrm{p} / \mathrm{p}^{0}=0.025$, reaching a maximum of 0.8 at $\mathrm{p} / \mathrm{p}^{0} \sim 0.4$, before 
decreasing to a fractional contribution of 0.6 . The maximum corresponds to $\sim 70 \%$ of the maximum amount adsorbed on the carbons. This is the isotherm region where the associative mechanism becomes significant. The contribution of the very slow kinetic component decreases from $\sim 0.7$ at $\mathrm{p} / \mathrm{p}^{0}=0.025$ to 0.2 at $\mathrm{p} / \mathrm{p}^{0} \sim 0.4$. This slow component is associated with the presence of $\mathrm{COOH}$ surface groups.

Figure 9 shows the variation of adsorption kinetics parameters with $\mathrm{p} / \mathrm{p}^{0}$ for the $\mathrm{GN}_{\mathrm{H}}$ sub-series. The exponent $\beta$ in the $\mathrm{SE}$ model increases from $\sim 0.5-0.6$ at low relative pressure to $\sim 0.9-1$ at $\mathrm{p} / \mathrm{p}^{0}>0.5$ for all the carbons in the series. The former indicates a distribution of relaxation times due to distribution of surface functional group characteristics, while the latter is very close to the LDF model, which has a single relaxation time. The rate constants decrease as surface coverage increases in the low $\mathrm{p} / \mathrm{p}^{0}$ region for all the carbons in the $\mathrm{G}$ Series. This is due to differences in the adsorption of water molecules on various functional groups with different properties at low relative pressure and the slower rates of associative hydrogen bonding of adsorbed water to other water molecules, which increased with increasing $\mathrm{p} / \mathrm{p}^{0}$. The exponent $\beta$ increases with increasing relative pressure but does not change significantly with oxygen content (see Figure 9b). Therefore, the kinetics can be described solely by the change in the rate constants.

TPD, FTIR and Boehm titration studies showed that the $\mathrm{GN}_{\mathrm{L}}$ sub-series had high concentrations of carboxylic functional groups. This is the main difference between the surface characteristics of the $\mathrm{GN}_{\mathrm{L}}$ and $\mathrm{GN}_{\mathrm{H}}$ sub series of carbons. The presence of carboxylic surface groups is also associated with higher Henry's law constants and this is related to higher adsorbate-adsorbent interactions. The two barriers associated with the DE kinetic model are attributed to differences in the interaction of carboxylic and other oxygen surface functional groups with $\mathrm{H}_{2} \mathrm{O}$. 


\subsubsection{Relationships between Kinetic Parameters and Oxygen Functional Groups}

Relative pressure $<0.2$ The Henry's law graphs are linear up to $\mathrm{p} / \mathrm{p}^{0}=0.2$ for all the carbons used in this study (see Figure 4). Figure 8 shows that the fast rate constant $\left(\mathrm{k}_{1}\right)$ decreases with increasing $\mathrm{p} / \mathrm{p}^{0}$ whereas the slow rate constant $\left(\mathrm{k}_{2}\right)$ does not change greatly for the $\mathrm{GN}_{\mathrm{L}}$ series in this region. The variation of the rate constants for pressure steps in the range $\mathrm{p} / \mathrm{p}^{0} 0-0.4$ with Henry's law constant, $\mathrm{K}_{\mathrm{H}}$, for the $\mathrm{GN}_{\mathrm{H}}$ sub series is shown in Figure 10. The SE rate constants for pressure increments at low $\mathrm{p} / \mathrm{p}^{0}$ decrease with increasing $\mathrm{K}_{\mathrm{H}}$ and hence adsorbate-adsorbent interactions. The trend gradually decreases with increasing $\mathrm{p} / \mathrm{p}^{0}$ and is no longer apparent at $\mathrm{p} / \mathrm{p}^{0}=0.4$. Similar correlations are observed between SE rate constant and oxygen content. The ratio of the $\mathrm{H}_{2} \mathrm{O}$ adsorbed at $\mathrm{p} / \mathrm{p}^{0}=0.2$ to total oxygen content on a mole basis ranged from $0.35-0.55$ for the GN series. The uptakes at $\mathrm{p} / \mathrm{p}^{0}=0.2$ increase in the range 4$20 \%$ of the total maximum uptake with increasing oxygen content. Therefore, the pressure range $\mathrm{p} / \mathrm{p}^{0}<0.2$ is where effects due to surface functional groups are dominant. This is consistent with a site-to-site hopping mechanism where the kinetics are slower for stronger adsorbate-adsorbent interactions. The Henry's law constant, which is directly related to adsorbate-adsorbent interactions, is linearly related to oxygen content for the $\mathrm{GN}_{\mathrm{H}}$ sub-series (see Figure 5a).

Relative pressure $>0.2$ The kinetic profiles for the $\mathrm{GN}_{\mathrm{L}}$ sub-series for $\mathrm{p} / \mathrm{p}^{0}>0.2$ fit the DE kinetic model even though the uptakes are $>0.25 \mathrm{x}$ maximum uptakes and the effects of the associative mechanism with adsorption of water molecules on adsorbed water become significant. It is evident that the differences in hydrogen bonding of $\mathrm{H}_{2} \mathrm{O}$ to surface groups also influence $\mathrm{H}_{2} \mathrm{O}-\mathrm{H}_{2} \mathrm{O}$ associative interactions.

Above $\mathrm{p} / \mathrm{p}^{0} \sim 0.2$ the trends in adsorption kinetic parameters with $\mathrm{K}_{\mathrm{H}}$ for the $\mathrm{GN}_{\mathrm{H}}$ series become progressively weaker and not observed for $\mathrm{p} / \mathrm{p}^{0}>0.4$ due to the 
increased importance of the associative adsorption mechanism (see Figure 10 and Supporting Information). This is shown in the variation of the gradient of the rate constant versus $\mathrm{K}_{\mathrm{H}}$ graphs, which decrease with increasing relative pressure indicating a lower dependence on surface chemistry at higher surface coverage. In the case of the $\mathrm{GN}_{\mathrm{H}}$ sub-series, the trends in kinetic parameters with oxygen content observed at low surface coverage are no longer observed due to the effects of associative adsorption. Confinement of water may influence the hydrogen bonded structure in nanotubes ${ }^{50}$ and molecular transport in pores. ${ }^{51,52}$ The increase in rate constant at high relative pressure corresponds to the plateau in the isotherm close to complete pore filling.

\subsubsection{The Role of Oxygen Surface Groups}

The adsorption of water vapour on surface oxygen functional groups in porous carbons involves hydrogen bonding of water molecules to surface functional groups and adsorbate water molecules. These interactions influence the shape of the adsorption isotherm and control the adsorption dynamics, which involves a site to site surface diffusion process. Surface groups which contain only oxygen hydrogen bonds, for example, carbonyl, adsorb water via $-\mathrm{C}=\mathrm{O}---\mathrm{H}-\mathrm{O}_{\text {water }} \mathrm{H}$-bond interactions. Adsorption of water molecules on phenolic and carboxylic surface functional groups depends on whether $\mathrm{OH}$ acts as a H-bond donor or oxygen acts as a H-bond acceptor. In addition, in the case of $-\mathrm{COOH}$, the $\mathrm{C}=\mathrm{O}$ may also $\mathrm{H}$-bond to $\mathrm{H}_{2} \mathrm{O}$. The pKa range for $\mathrm{COOH}$ groups in typical organic acids is in the range $3-6$ whereas the range for phenolic groups is 8 - 11. Ab initio studies for $\mathrm{CH}_{3} \mathrm{COOH}$ indicate that $-\mathrm{C}(=\mathrm{O})-\mathrm{O}-\mathrm{H}---$ $\mathrm{O}_{\text {water }}$ interaction $\left(28.8 \mathrm{~kJ} \mathrm{~mol}^{-1}\right)$ is much stronger than the average $-\mathrm{C}(\mathrm{O}-\mathrm{H})=\mathrm{O}---\mathrm{H}-$ $\mathrm{O}_{\text {water }}$ interaction $\left(21.8 \mathrm{~kJ} \mathrm{~mol}^{-1}\right)$, while $\mathrm{OH}$ acting as an acceptor was much weaker $\left(12.2 \mathrm{~kJ} \mathrm{~mol}^{-1}\right)$. The results indicate that $-\mathrm{COOH}$ groups act primarily as hydrogen bond donors. ${ }^{53}$ The aromatic carboxylic acids, for example, benzoic acid $(\mathrm{pKa}=$ 
4.19) are stronger than $\mathrm{CH}_{3} \mathrm{COOH}(\mathrm{pKa}=4.75)$ due to electron delocalization. Structural studies have revealed short $-\mathrm{C}(=\mathrm{O})-\mathrm{O}-\mathrm{H}---\mathrm{O}_{\text {water }}$ bonds in pyrazine di-, triand tetracarboxylic acid dihydrates and this was attributed polarization assistance. ${ }^{54}$ Benoit et al. ${ }^{55}$ studied the stability of water cluster formation around phenol $(\mathrm{pKa}=$ 9.89) using rigid body diffusion quantum Monte Carlo calculations. The calculations also indicated that $-\mathrm{CO}(-\mathrm{H})---\mathrm{H}-\mathrm{O}_{\text {water }}-\mathrm{H}$ is less stable than $-\mathrm{CO}-\mathrm{H}---\mathrm{O}_{\text {water }} \mathrm{H}_{2}$ with the possibility of weaker hydrogen bonding via the $\mathrm{H}$ of a water molecule to the aromatic ring. Similar hydrogen bonding interactions may take place between water molecules and surface functional groups in porous carbons.

The markedly different stabilities of water molecules hydrogen bonding to surface groups in activated carbons via the $\mathrm{O}$ in $\mathrm{H}_{2} \mathrm{O}$, compared with the $\mathrm{H}$ in $\mathrm{H}_{2} \mathrm{O}$ has a marked effect on $\mathrm{H}_{2} \mathrm{O}$ adsorption characteristics. The surface functional groups are divided into two categories a) primarily $\mathrm{H}$-bond donors (mainly $-\mathrm{COOH}$ and $-\mathrm{OH}$ groups) with possibilities of $\mathrm{O}$ acting as weaker $\mathrm{H}$-bond acceptors, and $\mathrm{b}$ ) $\mathrm{H}$-bond acceptors (carbonyl etc). The higher values for $\mathrm{K}_{\mathrm{H}}$ for the $\mathrm{GN}_{\mathrm{L}}$ series, which have been shown by TPD, FTIR and titration studies to contain carboxylic groups shows the effect of stronger hydrogen bonding of $\mathrm{H}_{2} \mathrm{O}$ to $\mathrm{COOH}$ surface groups $(-\mathrm{C}(=\mathrm{O})-\mathrm{O}-$ $\left.\mathrm{H}---\mathrm{O}_{\text {water }} \mathrm{H}_{2}\right)$ on the adsorption isotherm. The $\mathrm{COOH}$ groups $($ Benzoic acid $\mathrm{pKa}=$ 4.19) are much stronger acids phenolic groups (phenol $\mathrm{pKa}=9.89)$. In the case of the former, $\mathrm{C}(=\mathrm{O})-\mathrm{O}-\mathrm{H}---\mathrm{O}_{\text {water }} \mathrm{H}_{2}$ leads to the next associative adsorption step via $\mathrm{H}$ bonding $\mathrm{C}(=\mathrm{O})-\mathrm{O}-\mathrm{H}---\mathrm{OH}_{2}---\mathrm{OH}_{2}$ i.e via the $\mathrm{O}$ atom in $\mathrm{H}_{2} \mathrm{O}$ hydrogen bonding to $\mathrm{H}_{2} \mathrm{O}$ adsorbed on $-\mathrm{COOH}$ surface groups. Carbonyls groups interact with water via $\mathrm{C}=\mathrm{O}---\mathrm{H}-\mathrm{O}_{\text {water }} \mathrm{H}$, leading to associative hydrogen bonding of adsorbed water to either the $\mathrm{H}$ or $\mathrm{O}$ atoms of $\mathrm{H}_{2} \mathrm{O}$ hydrogen bonded to these groups. Therefore, the specific adsorbate-adsorbent interactions, which control whether $\mathrm{H}$ or $\mathrm{O}$ in $\mathrm{H}_{2} \mathrm{O}$ is hydrogen 
bonded to surface groups at low relative pressure, also influences whether the $\mathrm{H}$ or $\mathrm{O}$ in $\mathrm{H}_{2} \mathrm{O}$ is hydrogen bonded in the $\mathrm{H}_{2} \mathrm{O}-\mathrm{H}_{2} \mathrm{O}$ interactions in adsorption at high $\mathrm{p} / \mathrm{p}^{0}$. The adsorption kinetics are consistent with the $\mathrm{GN}_{\mathrm{L}}$ series containing a mixture of surface groups which act as both $\mathrm{H}$ bond donors and acceptors whereas the $\mathrm{GN}_{\mathrm{H}}$ series primarily contains $\mathrm{H}$-bond acceptors.

The water vapor adsorption isotherms and kinetics are determined by the strength of the adsorbate-adsorbent interaction and whether surface oxygen functional groups acts as hydrogen bond donors or acceptors. The concentration of functional groups and strength of adsorbate-adsorbent interactions influences transport of molecules between oxygen surface sites and hence adsorption kinetics. In the $\mathrm{GN}_{\mathrm{L}}$ series, the $-\mathrm{COOH}$ groups have a much stronger interaction with water molecules resulting in a slow adsorption component due to the strong $\mathrm{C}(=\mathrm{O})-\mathrm{O}-\mathrm{H}---\mathrm{O}_{\text {water }}$ hydrogen bond. The kinetic rate constants for specific pressure increments decrease linearly with increasing $\mathrm{K}_{\mathrm{H}}$ and oxygen content for the $\mathrm{GN}_{\mathrm{H}}$ sub series. $\mathrm{K}_{\mathrm{H}}$ has a linear relationship with oxygen concentration for the $\mathrm{GN}_{\mathrm{H}}$ sub-series. The rate determining step in the adsorption kinetics is the hopping between surface oxygen sites. The adsorption kinetics are slow when the concentration of surface sites is high and adsorbate-adsorbent interactions are strong.

\section{Conclusions}

A series of microporous carbons with oxygen functional groups modified systematically by thermal treatment was prepared with oxygen concentrations in the range 4.8 to $21.5 \mathrm{wt} \% \mathrm{db}$. The porous structure only changed to a very small extent in the series, thereby allowing the effect of functional groups on adsorption dynamics to be studied without the influence of differences in pore size distributions. 
The variation of Henry's law constants $\left(\mathrm{K}_{\mathrm{H}}\right)$ and DS an for water vapor adsorption, and total acidity values with oxygen concentration showed that the GN series should be subdivided into the $\mathrm{GN}_{\mathrm{L}}$ sub-series (GN387 and GN471) where the $\mathrm{K}_{\mathrm{H}}$ values were markedly higher than those for the $\mathrm{GN}_{\mathrm{H}}$ sub-series (GN562-GN894). This is attributed to the high carboxylic acid contents of $\mathrm{GN}_{\mathrm{L}}$ sub-series. The $\mathrm{GN}_{\mathrm{H}}$ series have linear correlations between $\mathrm{K}_{\mathrm{H}}, \mathrm{DS}$ a 0 and total acidity values and oxygen content. The ratio of pore volume obtained from water vapor adsorption to total pore volume decreased as the hydrophobic character of the surface increased. This is attributed to changes in adsorbate structure.

A set of nested kinetic models was used to describe the adsorption kinetics for the series of carbons. The $\mathrm{GN}_{\mathrm{L}}$ sub-series of carbons with high concentrations of carboxylic groups followed a double exponential model. This is consistent with dividing the surface functional groups into two classes; H-bond donors (carboxylic etc. groups) and H-bond acceptor (other functional groups such as carbonyl, phenolic etc.). The $\mathrm{GN}_{\mathrm{H}}$ sub-series of carbons followed a stretched exponential model, which is consistent with a distribution of relaxation times corresponding to heterogeneity in surface groups. The rate constants for $\mathrm{GN}_{\mathrm{H}}$ sub-series at low surface coverage $\left(\mathrm{p} / \mathrm{p}^{0}<\right.$ 0.2) decreased linearly with increasing Henry's law constant and adsorbate-adsorbent interaction energy. The initial interaction of $\mathrm{H}_{2} \mathrm{O}$ bonding to surface groups in adsorption at low $\mathrm{p} / \mathrm{p}^{0}$ may also influence the associative $\mathrm{H}_{2} \mathrm{O}-\mathrm{H}_{2} \mathrm{O}$ interactions at high $\mathrm{p} / \mathrm{p}^{0}$. 


\section{Acknowledgements}

YU would like to thank the $\mathrm{xxxx}$ for financial support.

\section{Supporting Information Available:}

Adsorption isotherm data, TPD results, FTIR spectra are given in Supporting

Information. This material is available free of charge via the Internet at

http://pubs.acs.org. 


\section{References}

(1) Fletcher, A. J.; Benham, M. J.; Thomas, K. M. J. Phys. Chem. B 2002, 106,7474

(2) Muller, E. A.; Rull, L. F.; Rega, L. F.; Gubbins, K. E. J Phys Chem 1996, 100, 1189.

(3) Lawson, C. G. Trans. Farad. Soc. 1936, 32, 473.

(4) King, A.; Lawson, C. G. Trans. Farad. Soc, 1934, 30, 1094.

(5) McDermot, H. L.; Arnell, A. C. J. Phys. Chem. 1954, 58, 492.

(6) Bansal, R. C.; Dhami, T. L.; Parkash, S. Carbon 1978, 16, 389.

(7) Kaneko, Y.; Ohbu, K.; Uekawa, N.; Fujie, K.; Kaneko, K. Langmuir 1995, 11, 708 .

(8) Puri, B. R.; Singh, S.; Mahajan, O. P. J. Indian Chem. Soc. 1965, 42, 427.

(9) Puri, B. R. Carbon 1966, 4, 391

(10) O'koye, I. P.; Benham, M.; Thomas, K. M. Langmuir 1997, 13, 4054.

(11) Harding, A. W.; Foley, N. J.; Norman, P. R.; Francis, D. C.; Thomas, K. M. Langmuir 1998, 14, 3858.

(12) Foley, N. J.; Forshaw, P. L.; Thomas, K. M.; Stanton, D.; Norman, P. R. Langmuir 1997, 13, 2083.

(13) Boehm, H. P. Carbon 1994, 32, 759.

(14) Benham, M. J.; Ross, D. K. Z. Phys. Chem. Neue Folge 1989, 163, 25.

(15) Lange Lange's Handbook of Chemistry, 15th ed.; McGraw-Hill: New

York, 1999

(16) IUPAC Manual of Symbols and Terminology. Pure Appl. Chem. 1972 $31,578$.

(17) Cazorla-Amoros, D.; Alcaniz-Monge, J.; Linares-Solano, A. Langmuir 1996, 12, 2820.

(18) Cazorla-Amoros, D.; Alcaniz-Monge, J.; de le Casa-Lillo M.A.; Linares-Solano, A. Langmuir 1998, 14, 4589.

(19) Linares-Solano, A.; Salinas Martínez de Lecea, C.; Monge, J. A.; Cazorla-Amorós, D. Tanso 1998, 185, 316.

(20) Barrett, E. P.; Joyner, L. G.; Halenda, P. P. J Phys Chem 1951, 73, 373.

(21) Dubinin, M. M.; Stoeckli, H. F. J. Coll. Interf. Sci. 1980, 75, 34.

(22) Leon y Leon, C. A.; Solar, J. M.; Calemma, V.; Radovic, L. R. Carbon 1992, 30, 797.

(23) Leon y Leon, C. A.; Radovic, L. R. Interfacial Chemistry and Electrochemistry of Carbon Surfaces. In Chemistry and Physics of Carbon; Thrower, P. A., Ed.; Marcel Dekker: New York, 1994; Vol. 24; pp 213.

(24) Boehm, H. P. In Advances in Catalysis; Eley, D. D., Pines, H., Weisz, P. B., Eds.; Academic Press: New York, 1966; Vol. 16; pp 179.

(25) Garten, V. A.; Weiss, D. E. Rev. Pure and Applied Chem. 1957, 7, 69.

(26) Bulko, J. B.; Herman, R. G.; Simmons, G. W.; Klier, K. J. Phys. Chem. 1979, 83,3118 .

(27) Otake, Y.; Jenkins, R. G. Carbon 1993, 31, 109.

(28) Boehm, H. P.; Knozinger, H. Catal. Sci.Technol. 1983, 4, 39.

(29) Turner, J. A.; Thomas, K. M. Langmuir 1999, 15, 6416.

(30) Xiao, B.; Boudou, J. P.; Thomas, K. M. Langmuir 2005, 21, 3400. 
(31) Calo, J. M.; Cazorla-Amoros, D.; Linares-Solano, A.; Roman-

Martinez, M. C.; Martinez de Lecea, C. S. Carbon 1997, 35, 543.

(32) Biniak, S.; Szymanski, G.; Siedlewski, J.; Swaiatkowski, A. Carbon 1997, 35, 1799.

$1985,23$.

(33) Akhter, M. S.; Keifer, J. R.; Chugtai, A. R.; Smith, D. M. Carbon

(34) Arnell, J. C.; McDermott, H. L. Can. J. Chem. 1952, 30, 177.

(35) Bradley, R. H.; Rand, B. Carbon 1991, 29, 1165.

(36) Berenguer-Murcia, A.; Fletcher, A. J.; Garcia-Martinez, J.; Cazorla-

Amoros, D.; Linares-Solano, A.; Thomas, K. M. J. Phys. Chem. B 2003, 107, 1012.

(37) Freeman, J. J.; Tomlinson, J. B.; Sing, K. S. W.; Theocharis, C. R.

Carbon 1993, 31, 865.

(38) Dubinin, M. M.; Serpinski, V. V. Carbon 1981, 19.

(39) Fletcher, A. J.; Cussen, E. J.; Prior, T. J.; Rosseinsky, M. J.; Kepert, C.

J.; Thomas, K. M. J. Am. Chem. Soc. 2001, 123, 10001.

(40) Fletcher, A. J.; Cussen, E. J.; Bradshaw, D.; Rosseinsky, M. J.;

Thomas, K. M. J. Am. Chem. Soc. 2004, 126, 9750.

(41) Klafter, J.; Shlesinger, M. F. Proc. Natl. Acad. Sci. 1986, 83, 848.

(42) Zhao, X.; Villar-Rodil, S.; Fletcher, A. J.; Thomas, K. M. J. Phys.

Chem. B 2006, 110, 9947.

(43) Reid, C. R.; Thomas, K. M. J. Phys. Chem. B 2001, 105, 10619.

(44) Reid, C. R.; O'koye, I. P.; Thomas, K. M. Langmuir 1998, 14, 2415.

(45) Reid, C. R.; Thomas, K. M. Langmuir 1999, 15, 3206.

(46) Chagger, H. K.; Ndaji, F. E.; Sykes, M. L.; Thomas, K. M. Carbon

1995, 33, 1405.

(47) Fletcher, A. J.; Thomas, K. M. Langmuir 1999, 15, 6908.

(48) Fletcher, A. J.; Thomas, K. M. Langmuir 2000, 16, 6253.

(49) Webster, C. E.; Drago, R. S.; Zerner, M. C. J. Am. Chem. Soc. 1998,

120,5509 .

(50) Byl, O.; Liu, J.-C.; Wang, Y.; Yim, W.-L.; Johnson, J. K.; J T Yates, J.

J Am. Chem. Soc. 2006, 128, 12090.

(51) Levinger, N. E. Science 2002, 298, 1722.

(52) Yui, H.; Guo, Y.; Koyama, K.; Sawada, T.; John, G.; Yang, B.;

Masuda, M.; Shimizu, T. Langmuir 2005, 21, 721.

(53) Rablen, P. R.; Lockman, J. W.; Jorgensen, W. L. J Phys Chem A 1998, 102,3782 .

(54) Vishweshwar, P.; Babu, N. J.; Nangia, A.; Mason, S. A.; Puschmann,

H.; Mondal, R.; Howard, J. A. K. J Chem Phys A 2004, 108, 9406.

(55) Benoit, D. M.; Clary, D. C. J. Phys. Chem. A 2000, 104, 5590. 


\section{List of Tables}

Table 1: Proximate analysis of carbons used in this study.

Table 2: Ultimate analysis of carbons used in this study (wt \% daf).

Table 3: Dubinin - Serpinsky analysis parameters obtained from the water vapor isotherms for carbons used in this study.

\section{List of Figures}

Figure 1: The variation of a) oxygen content (\%) and b) mass loss relative to carbon $\mathrm{G}$ with heat treatment temperature for carbons used in this study.

Figure 2: Total pore volume (from Langmuir equation and extrapolation to $\mathrm{p} / \mathrm{p}^{0}=1$ with $\rho_{\mathrm{N}_{2}}=0.8081 \mathrm{~g} \mathrm{~cm}^{-3}$ ), micropore volume $<0.7 \mathrm{~nm}$ (from D-R analysis of $\mathrm{CO}_{2}$ adsorption and extrapolation to $\mathrm{p} / \mathrm{p}^{0}=1$ with $\rho_{\mathrm{CO}_{2}}=1.023$ $\mathrm{g} \mathrm{cm}^{-3}$ ), micropore volume $<2 \mathrm{~nm}$ (from DR analysis of $\mathrm{N}_{2}$ adsorption and extrapolation to $\mathrm{p} / \mathrm{p}^{0}=1$ with $\rho_{\mathrm{N}_{2}}=0.8081 \mathrm{~g} \mathrm{~cm}^{-3}$ ) and water pore volume (isotherm extrapolated to $\mathrm{p} / \mathrm{p}^{0}=1$ with $\rho_{\mathrm{H}_{2} \mathrm{O}}=0.99707 \mathrm{~g} \mathrm{~cm}^{-3}$ ) trends obtained for carbons used in this study.

Figure 3: Functional group concentrations derived from selective neutralization results of carbons used in this study.

Figure 4: Isotherms for adsorption of water vapor on heat-treated carbons at $298 \mathrm{~K}$ for: $\square$ GN387; $\square$ GN471; GN562; $\bigcirc$ GN629; $\Delta$ GN665; $\triangle$ GN722; $\diamond \mathrm{GN} 894 ; \otimes \mathrm{G} 913 ; \diamond \mathrm{G}$.

Figure 5: The variation of a) Henry's Law constant and b) Dubinin-Serpinsky primary oxygen site concentration with oxygen content.

Figure 6: The variation of Henry's Law constant $\mathrm{K}_{\mathrm{H}}$ with a) carboxylic groups determined from titration measurements and b) TPD total $\mathrm{CO}_{2} / \mathrm{CO}$ ratio.

Figure 7: Kinetic profiles for water vapor adsorption: a) DE model fit for the kinetic profile for water vapor adsorption on GN471 at $298 \mathrm{~K}, \mathrm{p} / \mathrm{p}^{0}=0.125-$ 
$0 \cdot 150(\mathrm{p}=3.98-4.78 \mathrm{mbar})$ and $\mathrm{b}) \mathrm{SE}$ model fit for the kinetic profile for water vapor adsorption on GN629 at $298 \mathrm{~K}, \mathrm{p} / \mathrm{p}^{0}=0.125-0.150(\mathrm{p}=3.98$ -4.78 mbar).

Figure 8: (a) Main Component Contribution and (b) corresponding rate constant, $\mathrm{k}_{1}$, and (c) second rate constant, $\mathrm{k}_{2}$, calculated using DE model, for adsorption of water at $298 \mathrm{~K}$ on: $\diamond$ GN387; $\square$ GN471.

Figure 9: The Variation of kinetic parameters calculated using SE model, for adsorption of water at $298 \mathrm{~K} \mathrm{a}$ ) Rate constants, b) Exponent:: $\square$ GN562;

GN629; $\triangle$ GN665; $\nabla$ GN722; $\diamond$ GN894; $\bowtie$ G913.

Figure 10: The variation of SE rate constants with a) $\mathrm{K}_{H}$ and b) oxygen concentration, for the $\mathrm{GN}_{\mathrm{H}}$ series for water vapour adsorption at $298 \mathrm{~K}$. Pressure increments $(\square) \mathrm{p} / \mathrm{p}^{0}: 0-0.025 ;(\bigcirc) \mathrm{p} / \mathrm{p}^{0}: 0.075-0.1 ;(\triangle) \mathrm{p} / \mathrm{p}^{0}$ : $0.175-0.2 ;(\diamond) \mathrm{p} / \mathrm{p}^{0}: 0.25-0.30 ;(\boldsymbol{\square}) \mathrm{p} / \mathrm{p}^{0}: 0.3-0.4$; Graphs for other pressure increments are shown in Supporting Information 
Table 1: Proximate analysis of carbons used in this study.

\begin{tabular}{|c|c|c|c|}
\hline Sample & $\begin{array}{c}\text { Volatile Matter } \\
(\mathrm{wt} \% \mathrm{db})\end{array}$ & $\begin{array}{c}\text { Ash } \\
(\mathrm{wt} \% \mathrm{db})\end{array}$ & $\begin{array}{c}\text { Fixed Carbon } \\
(\mathrm{wt} \% \mathrm{db})\end{array}$ \\
\hline GN387 & $29 \cdot 20$ & 0.97 & $69 \cdot 82$ \\
\hline GN471 & 26.83 & 1.49 & $71 \cdot 68$ \\
\hline GN562 & $23 \cdot 17$ & 1.48 & $75 \cdot 35$ \\
\hline GN629 & $21 \cdot 50$ & 1.47 & $77 \cdot 03$ \\
\hline GN665 & $19 \cdot 75$ & $1 \cdot 73$ & $78 \cdot 52$ \\
\hline GN722 & 17.92 & 0.97 & $81 \cdot 11$ \\
\hline GN894 & $8 \cdot 36$ & 1.44 & $90 \cdot 20$ \\
\hline G913 & 2.47 & 3.43 & $94 \cdot 10$ \\
\hline G & 4.67 & 2.96 & 92.37 \\
\hline
\end{tabular}

$\mathrm{wt} \% \mathrm{db}=$ weight percent, dry basis

Table 2: Ultimate analysis of carbons used in this study (wt \% daf).

\begin{tabular}{|c|c|c|c|c|c|}
\hline Sample & $\mathrm{C}$ & $\mathrm{N}$ & $\mathrm{H}$ & $\mathrm{O}$ & Total \\
\hline GN387 & $77 \cdot 21$ & 1.03 & $1 \cdot 30$ & 21.49 & 101.03 \\
\hline GN471 & $80 \cdot 02$ & 1.00 & $1 \cdot 10$ & $18 \cdot 62$ & $100 \cdot 74$ \\
\hline GN562 & $83 \cdot 35$ & $1 \cdot 03$ & $0 \cdot 81$ & $16 \cdot 48$ & $101 \cdot 67$ \\
\hline GN629 & 84.09 & 1.03 & $0 \cdot 84$ & $14 \cdot 76$ & $100 \cdot 72$ \\
\hline GN665 & $85 \cdot 35$ & 1.03 & $0 \cdot 84$ & $14 \cdot 72$ & 101.94 \\
\hline GN722 & $86 \cdot 08$ & 1.03 & 0.77 & $12 \cdot 28$ & $100 \cdot 16$ \\
\hline GN894 & 92.96 & $1 \cdot 13$ & 0.76 & $4 \cdot 79$ & $99 \cdot 64$ \\
\hline G913 & $98 \cdot 11$ & $0 \cdot 24$ & 0.41 & $0 \cdot 39$ & $99 \cdot 15$ \\
\hline $\mathrm{G}$ & $96 \cdot 31$ & 0.23 & 0.64 & $2 \cdot 81$ & 99.99 \\
\hline
\end{tabular}

Table 3: Dubinin-Serpinsky analysis parameters obtained from the water vapor isotherms for carbons used in this study.

\begin{tabular}{|c|c|c|}
\hline Sample & $A_{0} \mathrm{D}-\mathrm{S}\left(\mathrm{mmol} \mathrm{g}^{-1}\right)$ & $\mathrm{p} / \mathrm{p}^{0}$ range \\
\hline GN387 & $31 \cdot 81 \pm 2 \cdot 62$ & $0 \cdot 17-0.40$ \\
\hline GN471 & $17 \cdot 99 \pm 1 \cdot 34$ & $0 \cdot 17-0.40$ \\
\hline GN562 & $4.30 \pm 0.13$ & $0 \cdot 15-0.40$ \\
\hline GN629 & $3.86 \pm 0.14$ & $0 \cdot 15-0.40$ \\
\hline GN665 & $3.47 \pm 0 \cdot 17$ & $0 \cdot 15-0.40$ \\
\hline GN722 & $3.30 \pm 0.18$ & $0 \cdot 15-0.40$ \\
\hline GN894 & $1.77 \pm 0.07$ & $0 \cdot 25-0.55$ \\
\hline G913 & $2 \cdot 01 \pm 0 \cdot 13$ & $0.40-0.60$ \\
\hline
\end{tabular}




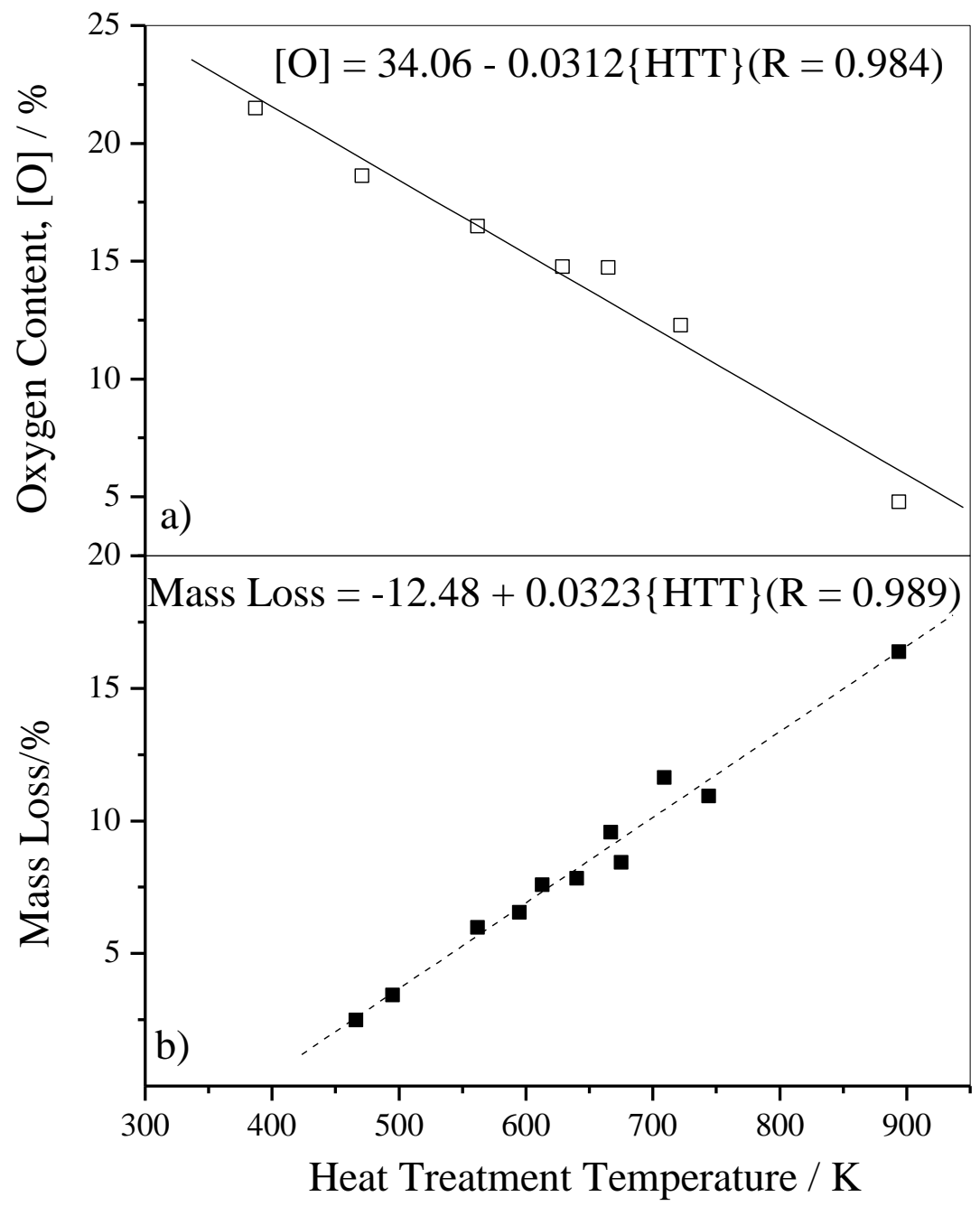

Figure 1: The variation of a) oxygen content (\%) and b) mass loss relative to carbon $\mathrm{G}$ with heat treatment temperature for carbons used in this study. 


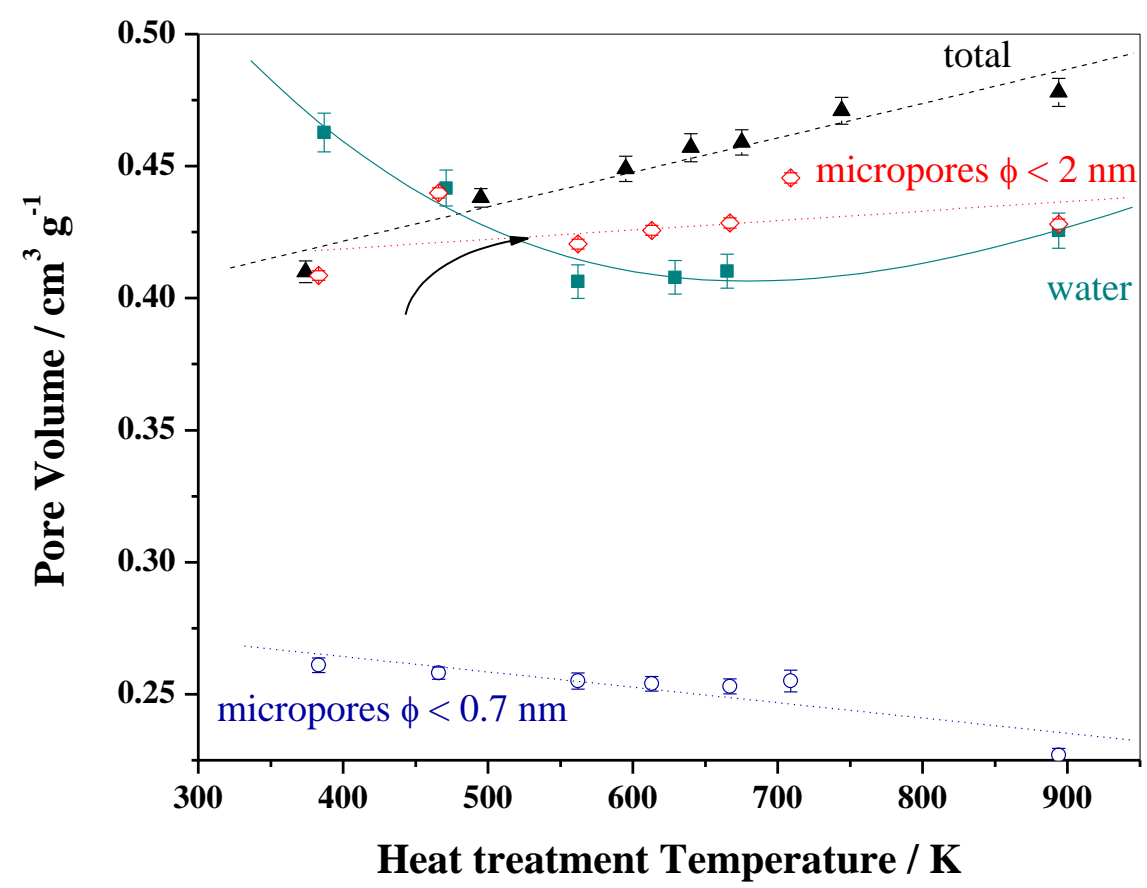

Figure 2: Total pore volume (from Langmuir equation and extrapolation to $\mathrm{p} / \mathrm{p}^{0}=1$ with $\rho_{\mathrm{N}_{2}}=0.8081 \mathrm{~g} \mathrm{~cm}^{-3}$ ), micropore volume $<0.7 \mathrm{~nm}$ (from DR analysis of $\mathrm{CO}_{2}$ adsorption and extrapolation to $\mathrm{p} / \mathrm{p}^{0}=1$ with $\rho_{\mathrm{CO}_{2}}=1.023 \mathrm{~g} \mathrm{~cm}^{-3}$ ), micropore volume $<2 \mathrm{~nm}$ (from $\mathrm{D}-\mathrm{R}$ analysis of $\mathrm{N}_{2}$ adsorption and extrapolation to $\mathrm{p} / \mathrm{p}^{0}=1$ with $\rho_{\mathrm{N}_{2}}=0.8081 \mathrm{~g} \mathrm{~cm}^{-3}$ ) and water pore volume (isotherm extrapolated to $\mathrm{p} / \mathrm{p}^{0}=1$ with $\rho_{\mathrm{H}_{2} \mathrm{O}}=0.99707 \mathrm{~g} \mathrm{~cm}^{-3}$ ) trends obtained for carbons used in this study. 


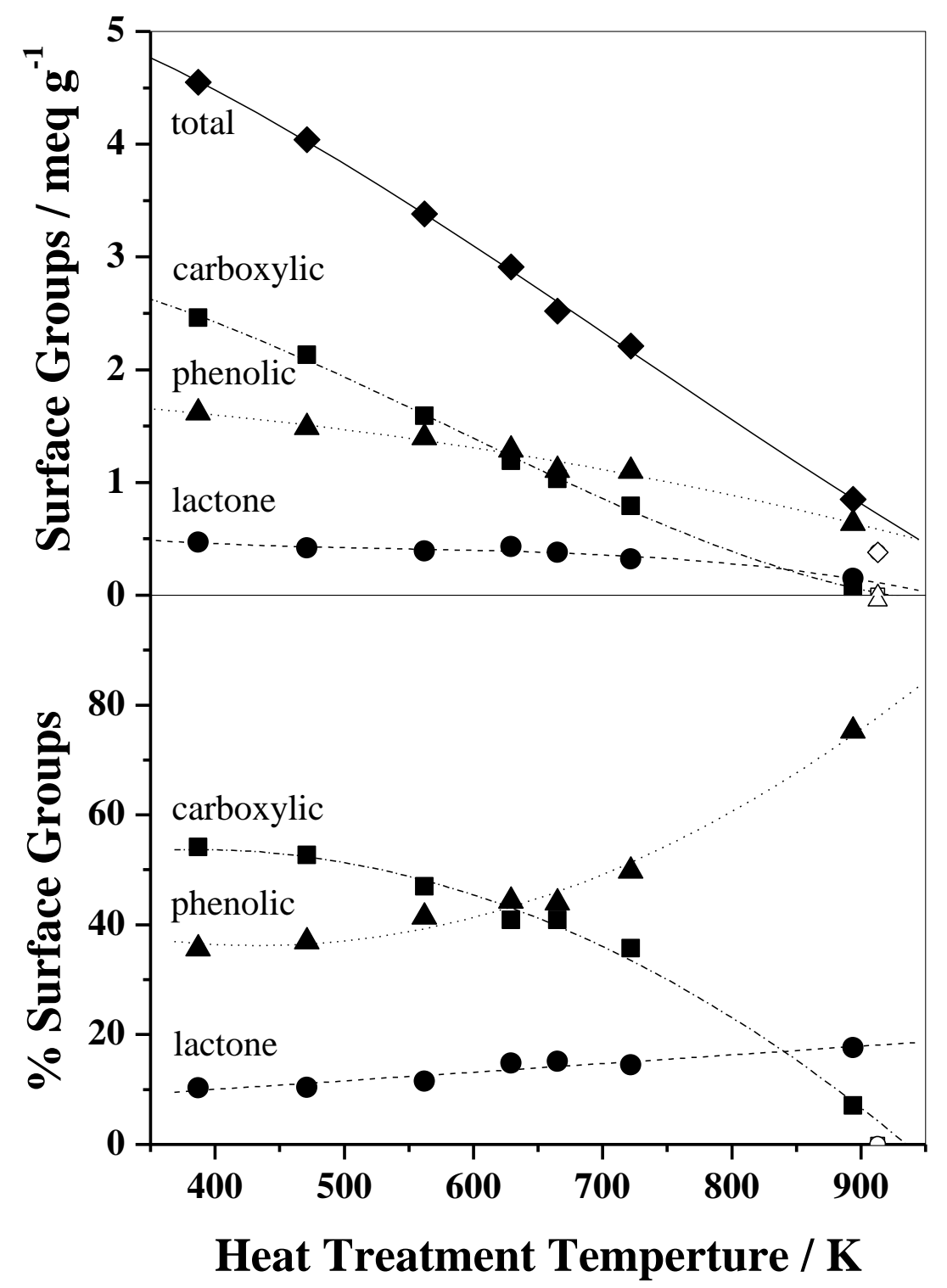

Figure 3: Functional group concentrations derived from selective neutralization results of carbons used in this study. 


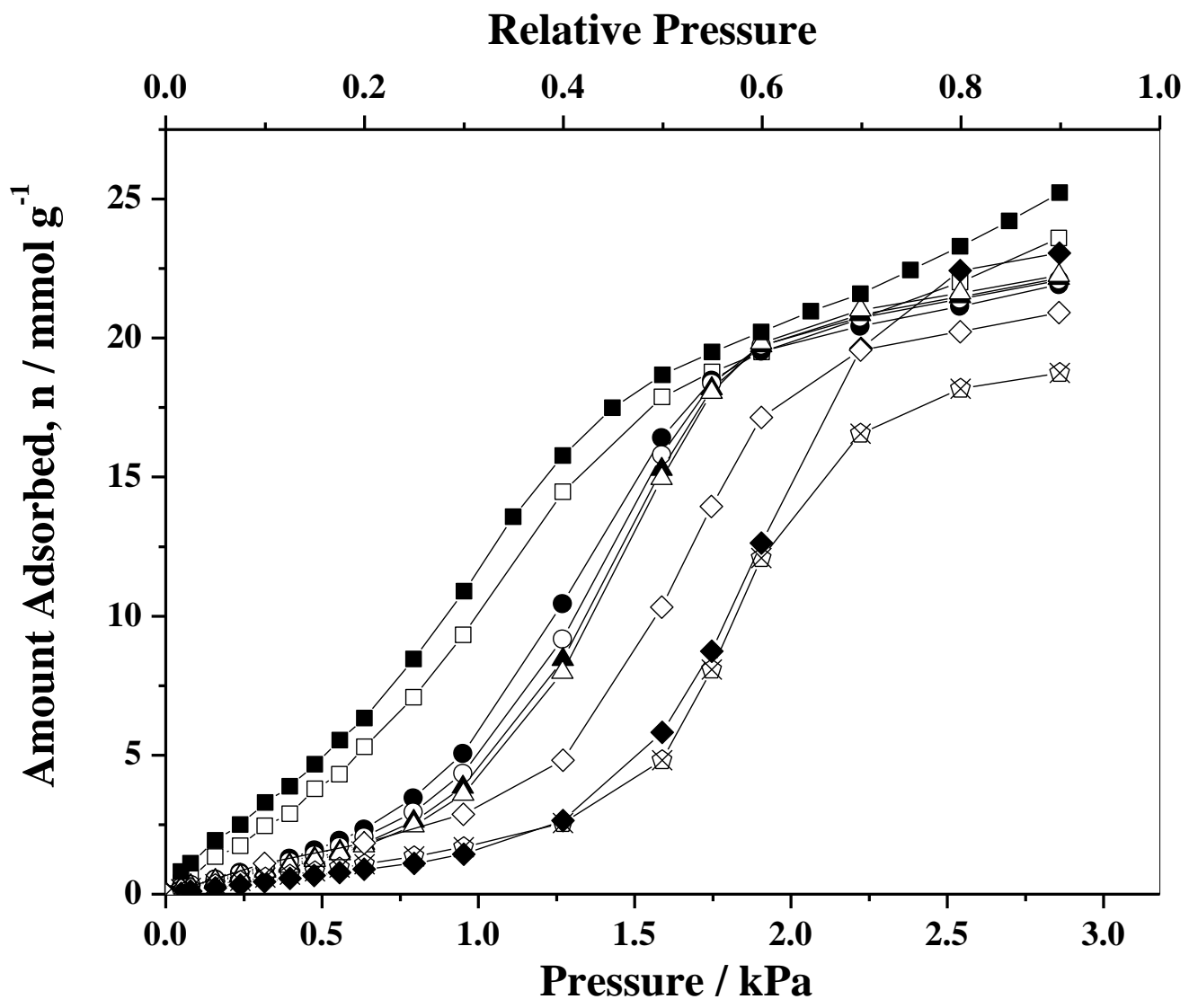

Figure 4: Isotherms for adsorption of water vapor on heat-treated carbons at $298 \mathrm{~K}$ for: $\square \mathrm{GN} 387 ; \square \mathrm{GN} 471 ; \bigcirc \mathrm{GN} 562 ; \bigcirc \mathrm{GN} 629 ; \boldsymbol{\Delta} \mathrm{GN} 665 ; \triangle \mathrm{GN722}$; $\diamond \mathrm{GN} 894 ; \otimes \mathrm{G} 913 ; \diamond \mathrm{G}$. 

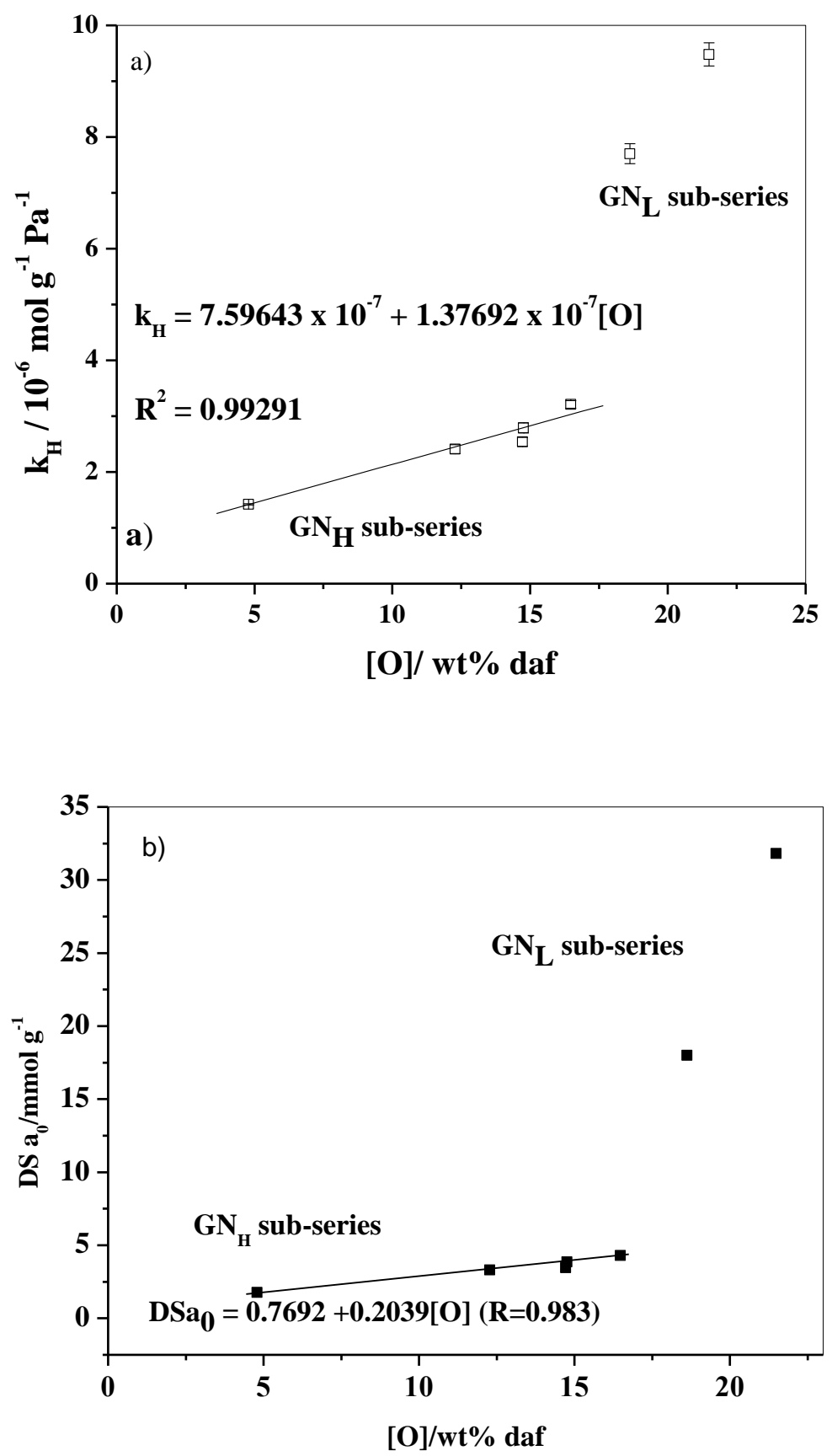

Figure 5: The variation of a) Henry's Law constant and b) Dubinin-Serpinsky primary oxygen site concentration with oxygen content. 

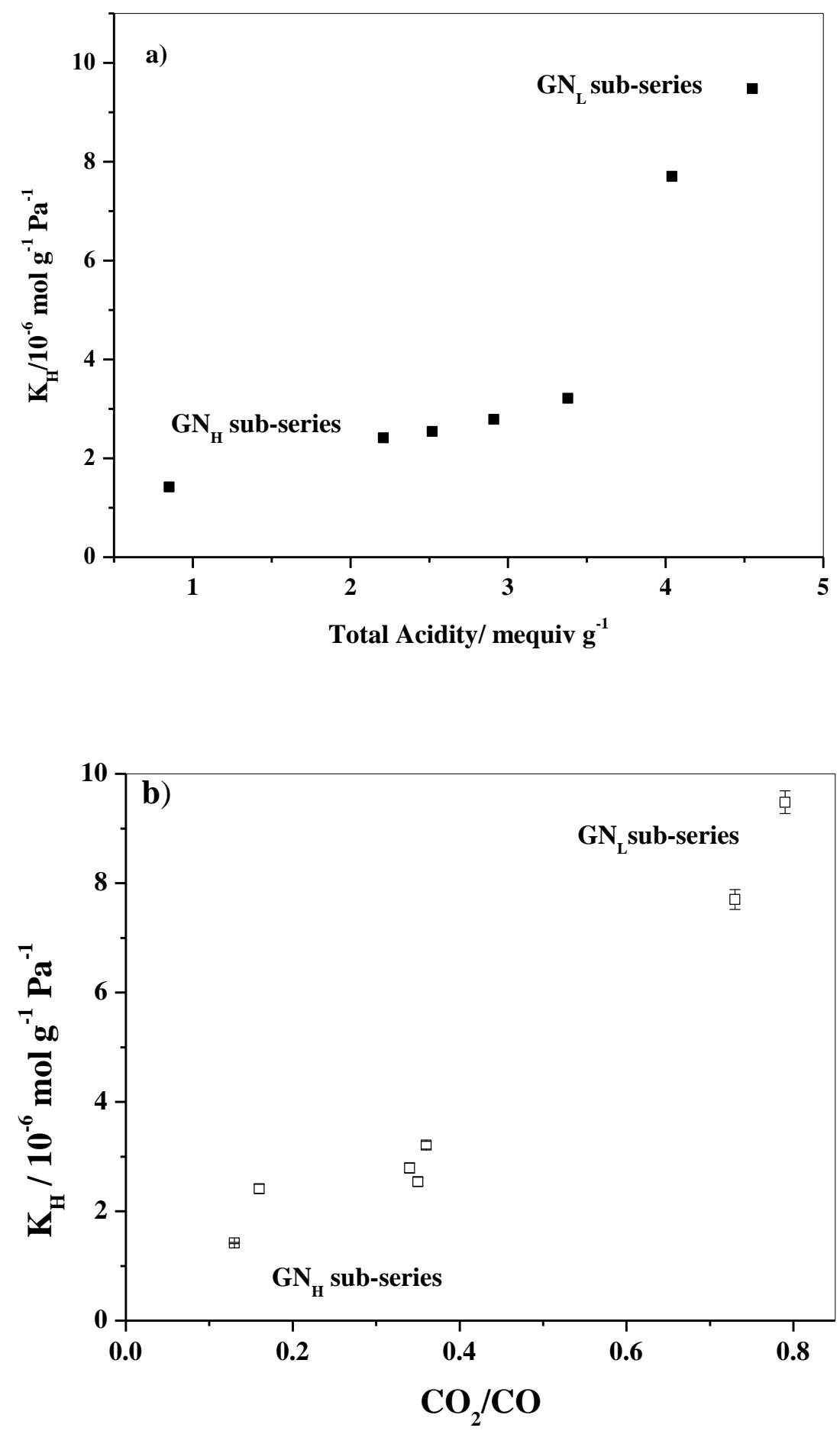

Figure 6: The variation of Henry's Law constant $\mathrm{K}_{\mathrm{H}}$ with a) total acidity determined from titration measurements and b) TPD total $\mathrm{CO}_{2} / \mathrm{CO}$ ratio. 


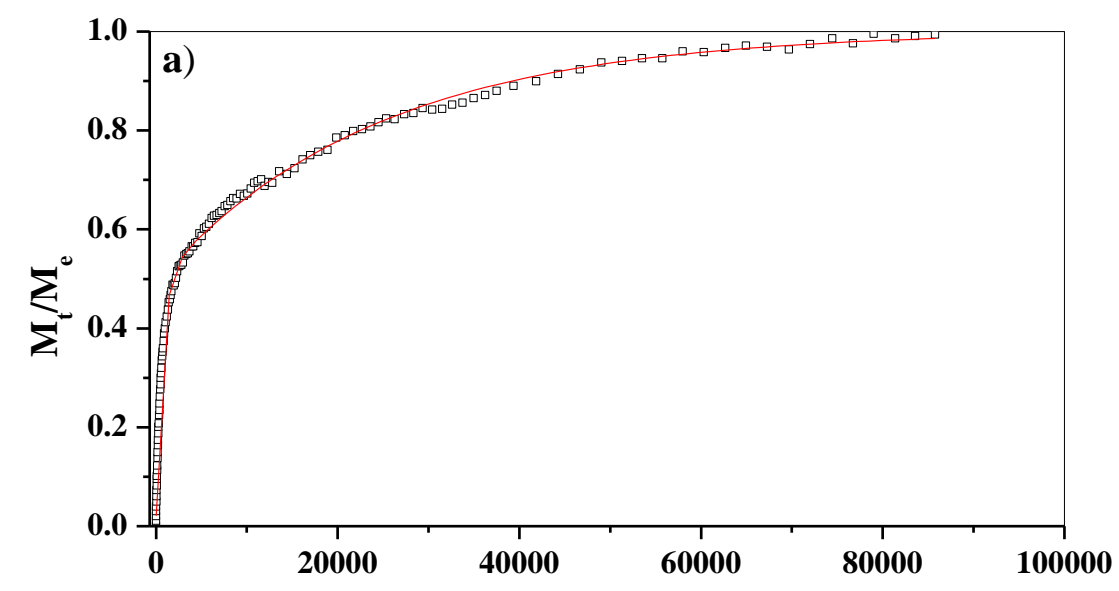

Time / s
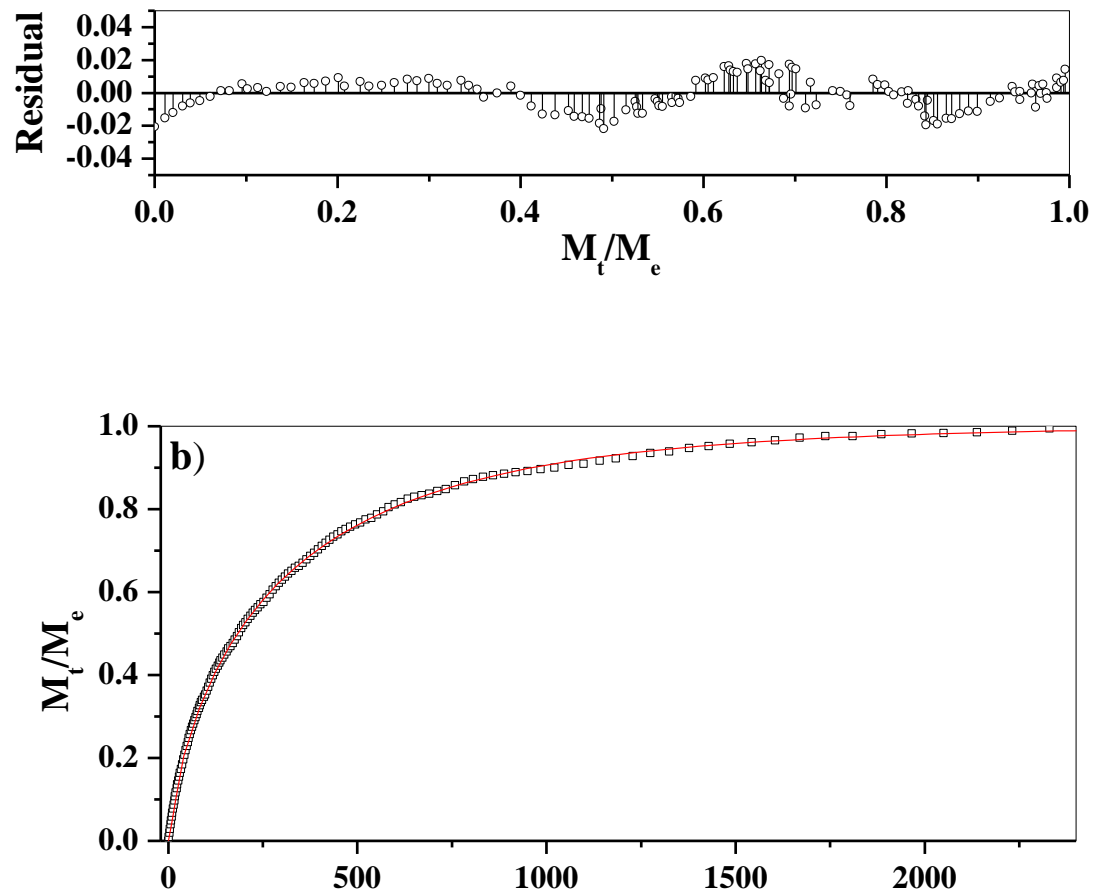

Time / s

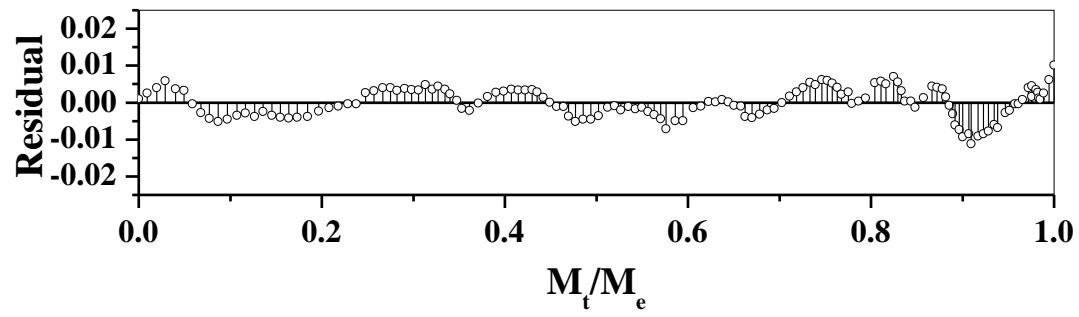

Figure 7: Kinetic profiles for water vapor adsorption: a) DE model fit for the kinetic profile for water vapor adsorption on GN471 at $298 \mathrm{~K}, \mathrm{p} / \mathrm{p}^{0}=0.125-$ $0.150(\mathrm{p}=3.98-4.78 \mathrm{mbar}$ ) and $\mathrm{b}) \mathrm{SE}$ model fit for the kinetic profile for water vapor adsorption on GN629 at $298 \mathrm{~K}, \mathrm{p} / \mathrm{p}^{0}=0.125-0.150(\mathrm{p}=3.98$ -4.78 mbar). 


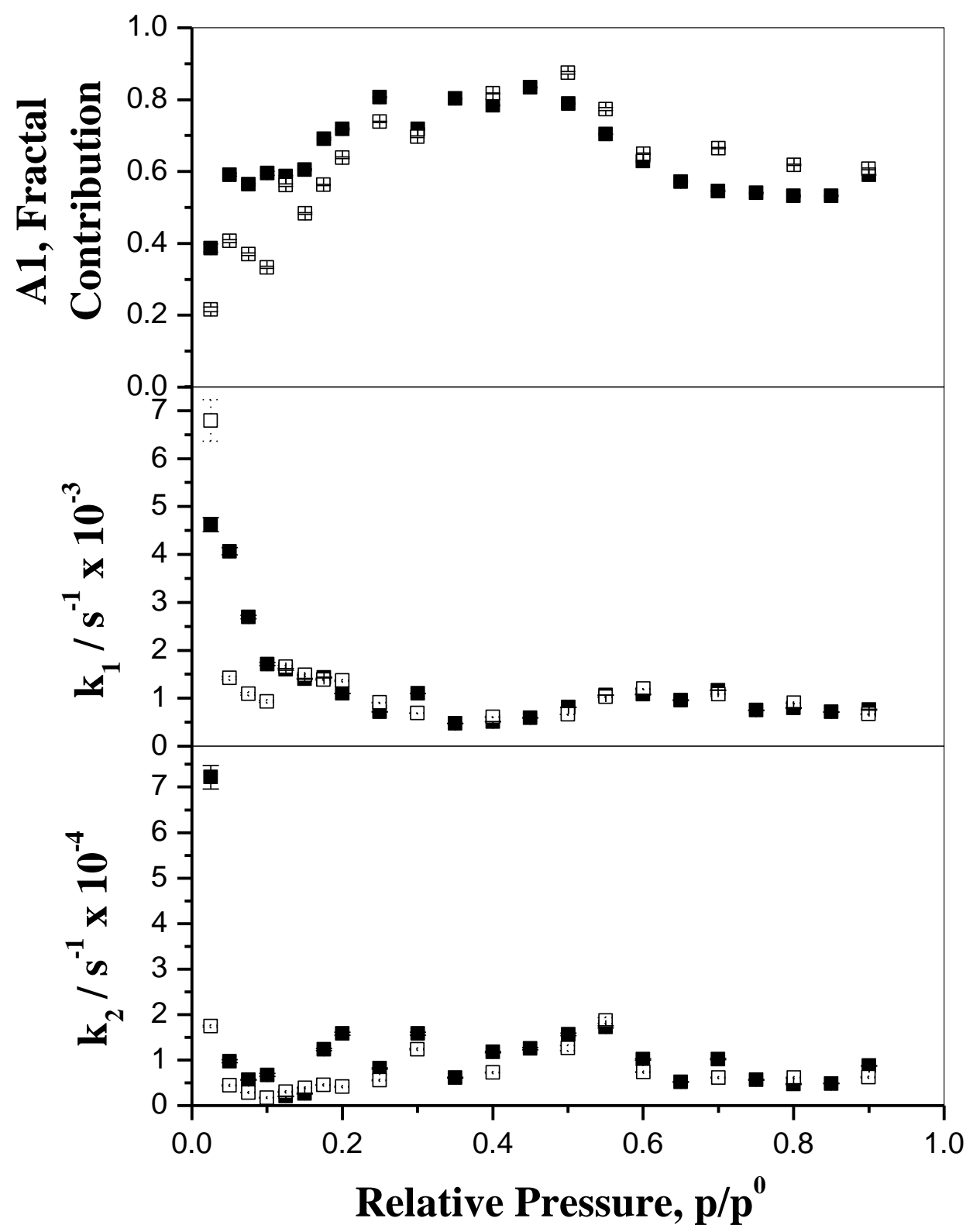

Figure 8: (a) Main component contribution and (b) corresponding rate constant, $\mathrm{k}_{1}$, and (c) second rate constant, $\mathrm{k}_{2}$, calculated using DE model, for adsorption of water at $298 \mathrm{~K}$ on: $\diamond \mathrm{GN} 387$; $\square$ GN471. 


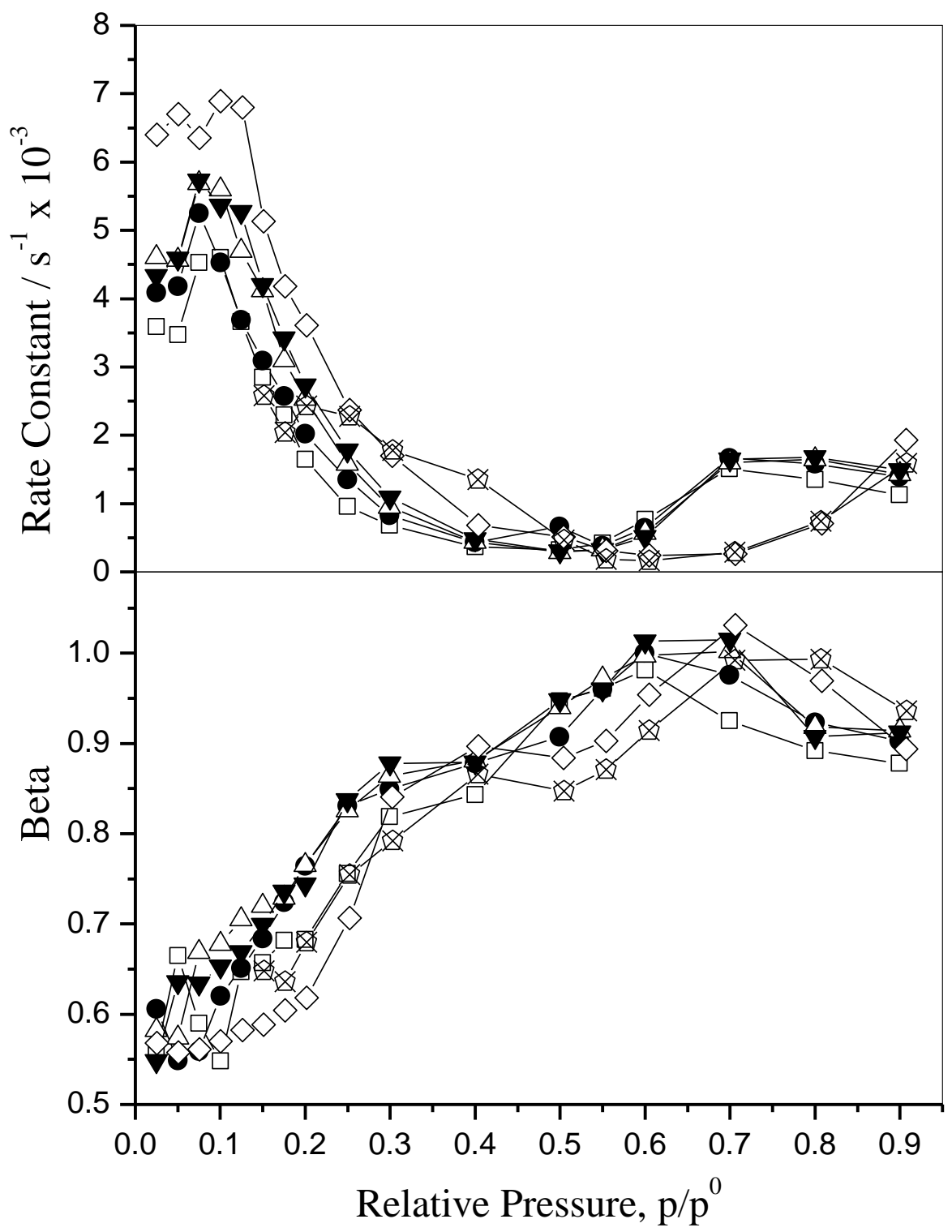

Figure 9: The Variation of kinetic parameters calculated using SE model, for adsorption of water at $298 \mathrm{~K}$ a) Rate constants, b) Exponent:: $\square$ GN562; GN629; $\triangle$ GN665; $\nabla$ GN722; $\diamond$ GN894; $\bowtie$ G913. 

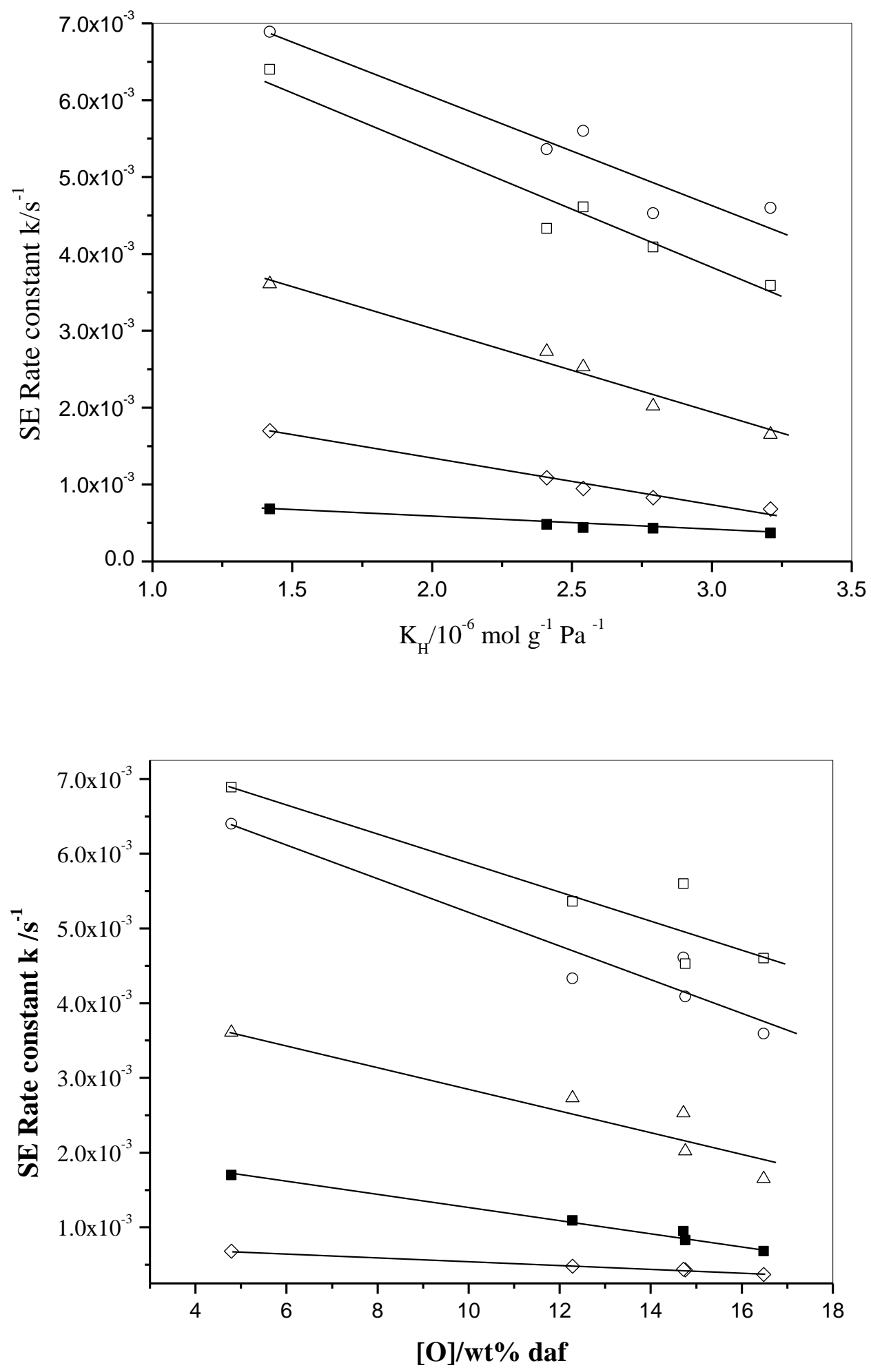

Figure 10 The variation of SE rate constants with a) $\mathrm{K}_{\mathrm{H}}$ and b) oxygen concentration, for the $\mathrm{GN}_{\mathrm{H}}$ series for water vapour adsorption at $298 \mathrm{~K}$. Pressure increments $(\square)$ $\mathrm{p} / \mathrm{p}^{0}: 0-0.025 ;(\bigcirc) \mathrm{p} / \mathrm{p}^{0}: 0.075-0.1 ;(\triangle) \mathrm{p} / \mathrm{p}^{0}: 0.175-0.2 ;(\diamond) \mathrm{p} / \mathrm{p}^{0}: 0.25-0.30 ;(\boldsymbol{\square}) \mathrm{p} / \mathrm{p}^{0}:$ 0.3-0.4; Graphs for other pressure increments are shown in Supporting Information 